\title{
Characterization of Intrastriatal Recombinant Adeno-Associated Virus-Mediated Gene Transfer of Human Tyrosine Hydroxylase and Human GTP-Cyclohydrolase I in a Rat Model of Parkinson's Disease
}

\author{
R. J. Mandel, K. G. Rendahl, S. K. Spratt, R. O. Snyder, L. K. Cohen, and S. E. Leff \\ Department of Gene Therapy Applications, Cell Genesys Inc., Foster City, California 94404
}

To achieve local, continuous L-DOPA delivery in the striatum by gene replacement as a model for a gene therapy for Parkinson's disease, the present studies used high titer purified recombinant adeno-associated virus (rAAV) containing cDNAs encoding human tyrosine hydroxylase (hTH) or human GTPcyclohydrolase I [GTPCHI, the rate-limiting enzyme for tetrahydrobiopterin $\left(\mathrm{BH}_{4}\right)$ synthesis] or both to infect the 6-OHDA denervated rat striatum. Striatal TH and GTPCHI staining was observed 3 weeks after rAAV transduction, with little detectable perturbation of the tissue. Six months after intrastriatal $\mathrm{rAAV}$ transduction, TH staining was present but apparently reduced compared with the 3 week survival time. In a separate group of animals, striatal TH staining was demonstrated 1 year after rAAV transduction. Double staining studies using the neuronal marker NeuN indicated that $>90 \%$ of rAAV-transduced cells expressing hTH were neurons. Microdialysis experiments indicated that only those lesioned animals that received the mixture of MD-TH and MD-GTPCHI vector displayed $\mathrm{BH}_{4}$ independent in vivo L-DOPA production (mean $\sim 4-7 \mathrm{ng} / \mathrm{ml}$ ). Rats that received the $\mathrm{hTH}$ rAAV vector alone produced measurable L-DOPA (mean $\sim 1-4 \mathrm{ng} / \mathrm{ml}$ ) only after receiving exogenous $\mathrm{BH}_{4}$. L-Aromatic amino acid decarboxylase blockade, but not $100 \mathrm{~mm} \mathrm{KCl-induced} \mathrm{depolarization,} \mathrm{enhanced} \mathrm{L-DOPA}$ overflow, and animals in the non-hTH groups (GTPCHI and alkaline phosphatase) yielded minimal L-DOPA. Although elevated L-DOPA was observed in animals that received mixed $\mathrm{hTH}$ and hGTPCHI rAAV vectors, there was no reduction of apomorphine-induced rotational behavior 3 weeks after intrastriatal vector injection. These data demonstrate that purified rAAV, a safe and nonpathogenic viral vector, mediates longterm striatal hTH transgene expression in neurons and can be used to successfully deliver L-DOPA to the striatum.

Key words: recombinant adeno-associated virus; tyrosine hydroxylase; GTP-cyclohydrolase I; gene therapy; Parkinson's disease; L-dihydroxyphenylalanine
The concept of gene therapy in the CNS for the treatment of neurological disorders is based on the fact that de novo expression of a normally quiescent gene can allow local continuous delivery of a gene product within the blood-brain barrier (Gage et al., 1987). The delivery of therapeutic proteins or amino acids may be useful in treating many different CNS disorders. Thus animal models of Parkinson's disease (PD) provide one of the most attractive targets for development of a gene therapy treatment. This focus on animal models of PD is a natural extension of the extensive preclinical research and clinical experience of transplantation of fetal substantia nigra tissue in PD (Björklund, 1991; Freed et al., 1992; Spencer et al., 1992; Widner et al., 1992; Kordower et al., 1995). Transplantation of fetal ventral mesencephalic dopamine (DA) neurons for the treatment of PD has demonstrated that (1) the existing animal models of PD might be

\footnotetext{
Received Jan. 22, 1998; revised March 12, 1998; accepted March 23, 1998.

This work was performed at Somatix Therapy Corporation, which has merged with Cell Genesys Inc. We gratefully acknowledge the technical assistance of Dorothy Clevenger and Terry Jaret (in vivo work); Fang-Fang Wu (HPLC); Dea Nagy, Matthew Morton, Joyce Conway (histology); Ya-Li Lee, Xiadong Xu (constructs); Brian Kaspar, Barbara Sloan, Shangzhen Zhou (vector production); and Melinda Van Roey, Robert Ayers, and Dwight Dove (animal care). Additional thanks to Michele Libonati for her prodigious administrative support of our research program.

Correspondence should be addressed to R. J. Mandel, Department of Gene Therapy Applications, Cell Genesys Inc., 342 Lakeside Drive, Foster City, CA 94404.

Copyright (ㄷ) 1998 Society for Neuroscience $\quad 0270-6474 / 98 / 184271-14 \$ 05.00 / 0$
}

clinically predictive, (2) a surgical intervention that results in the delivery of more DA directly to the striatum may be clinically relevant, and (3) the neurosurgical procedures involved are tolerated in patients (Björklund, 1991; Freed et al., 1992; Spencer et al., 1992; Widner et al., 1992; Kordower et al., 1995). Thus, the transition from basic research to clinical research with fetal transplantation in PD has removed some of the technical uncertainties associated with the development of gene replacement as a viable strategy for PD. Moreover, importantly for a novel strategy such as gene therapy in the human arena, there is a known therapy for PD that is potentially amenable to delivery via gene transfer techniques, i.e., systemic L-DOPA.

If a gene therapy for PD is to be developed, intrastriatal gene transfer must be demonstrated to be safe, to enable delivery of therapeutic levels of L-DOPA, to show durable transgene expression, and ultimately to allow control over the L-DOPA dosage. Recent studies have noted that retrovirally transduced primary fibroblasts expressing transgenic hTH produce L-DOPA only when either exogenous tetrahydrobiopterin $\left(\mathrm{BH}_{4}\right)$ is supplied or the rate-limiting enzyme in the $\mathrm{BH}_{4}$ synthetic pathway, GTPcyclohydrolase I (GTPCHI), is co-expressed (Uchida et al., 1992; Bencsics et al., 1996; Leff et al., 1998). It appears that $\mathrm{BH}_{4}$ levels outside of nigrostriatal terminals may be insufficient to support activation of transgenic $\mathrm{TH}$ expressed in other compartments. Consequently, the present study examined whether hGTPCHI co-expression with hTH is required to produce L-DOPA. Ample 
evidence suggests that continuous L-DOPA delivery might be advantageous in PD (Chase et al., 1989; Chase et al., 1993; Schuh and Bennett, 1993; Obeso et al., 1994), whereas site-specific intrastriatal delivery should obviate any side effects caused by extrastriatal DA agonism. Here we describe efforts to fulfill most of these requirements for a gene therapy strategy to deliver L-DOPA locally to the DA-denervated rat striatum using recombinant adeno-associated virus (rAAV) vectors.

Wild-type AAV (wt-AAV) is a nonpathogenic parvovirus that requires helper functions from adenoviruses (Ad) or herpes simplex virus (HSV) to complete its life cycle and produce progeny. As described previously in detail, the construction of an rAAV vector entails removing all of the wt-AAV genome with the exception of the inverted terminal repeats (ITRs) and replacing the deleted genes with the transgene via a well described vector production scheme (Muzyczka, 1992). The applicability and safety of rAAV vectors for use in human gene therapy stems from several features associated with its production and infection characteristics. At least two unlikely events must occur in vivo for rAAV to become replication competent and create a productive infection (Muzyczka, 1992). Because all the viral genes are removed in the case of rAAV, and hTH and hGTPCHI are cytoplasmic enzymes, foreign proteins should not be presented by an infected cell as can be the case with other viral vector systems (Yang et al., 1994; Neve and Geller, 1996). Thus the possibility of a host immune response after infection should be limited. Moreover, because rAAV is a DNA vector, it can infect and express in nondividing cells, which is an essential prerequisite for use in the CNS. Finally, if an extremely improbable reversion to wt virus occurred in vivo after an $\mathrm{AAV}$ injection, although CNS infection with wt-AAV has never been observed, this hypothetical wt-AAV infection may be harmless because wt-AAV is not known to be pathogenic.

The present study reports that (1) rAAV-mediated hTH and hGTPCHI expression was sufficient to enable in vivo measurement of L-DOPA via microdialysis; (2) transgene expression, as demonstrated by immunocytochemistry was observed at 3 weeks, 6 months, and 1 year after intrastriatal rAAV transduction; (3) the vast majority $(>90 \%)$ of the striatal cells that expressed hTH were also shown to express the neuronal marker NeuN (Mullen et al., 1992), but few expressed the glial marker, glial fibrillary acidic protein (GFAP, 1\%); and (4) there was no apparent host reaction to the rAAV injections based on observations taken solely from Nissl-stained sections.

\section{MATERIALS AND METHODS}

$r A A V$ production. The construction of MD-human alkaline phosphatase (hAP) is described elsewhere (Samulski et al., 1989; Hofland et al., 1997). pMD-hTH and pMD-hGTPCHI were constructed with a cassette composed of the following sequences: a CMV immediate early promoter/ enhancer [nucleotide (nt) positions -670 to +72 ; GenBank accession no. X03922] from $\mathrm{pBC12/CMV/IL-2} \mathrm{(Cullen,} \mathrm{1986);} \mathrm{a} \mathrm{small} \mathrm{region} \mathrm{of} \mathrm{hu-}$ man $\beta$-globin exon 2 and a shortened second intervening sequence (nt positions 62613-62772 plus 63088-63532; GenBank accession no. J02400); $\beta$-globin exon 3, the hTH or hGTPCHI cDNAs, and the polyA signal sequence from the bovine growth hormone gene. cDNAs for hTH (from $\mathrm{pRc} / \mathrm{TH} / 317$; a gift of M. Rosenberg, University of California San Diego) and GTPCHI (see below) were obtained from MFG-S-based retroviral vectors that contain the respective transgenes precisely linked to the env translational start and were inserted into exon 3 of the $\beta$-globin sequence (position 63530) at a site in the MD cassette that was modified by PCR to include restriction sites for PmlI, EcoRI, and BglII. The entire MD expression cassette was inserted between the AAV inverted terminal repeats of psub201 (Samulski et al., 1989).

A full-length cDNA encoding an active isoform of human GTP cyclo- hydrolase I was isolated using PCR amplification from a "Quick clone" (CloneTech) liver cDNA library. The primers (GTPCHI 1.1, TCCATGGAGAAGGGCCCTGTGC, GenBank accession no. S44053, nt 65-86; and GTPCHa2.2, CTGATCAAATCTGGCAGTACGATCGGCAACC, GenBank accession no. S44049, complement to nt 771-751 plus linker sequence) were based on published sequence (Gutlich et al., 1994), and they included sequence encoding restriction sites $N c o$ I at the N-terminal encoding end and $B c l \mathrm{I}$ and $B g l \mathrm{II}$ at the end closest to the $\mathrm{C}$ terminus of the encoded protein; $50 \mathrm{bp}$ of $3^{\prime}$ noncoding sequence is included in this sequence, which is $810 \mathrm{bp}$. It was sequenced in its entirety in both strands after cloning into the vector pCRII (Invitrogen Corp., San Diego, CA). pMD-hTH was constructed with a cassette identical to pMD-hGTPCHI, except that a cDNA encoding human TH2 (Samulski et al., 1989; Wolff et al., 1989) was inserted in place of hGTPCHI.

rAAV vectors were prepared according to Snyder et al. (1997) and Mandel et al. (1997). The purity of the rAAV was determined as follows. The rAAV vectors banded with a density of $1.42 \mathrm{gm} / \mathrm{ml}$ on the $\mathrm{CsCl}$ gradients as determined by refractometry, which is similar to the density for wt-AAV. The rAAV preparations were stable to the heat treatment used to inactivate remaining Ad by two criteria: (1) the rAAV remained resistant to treatment with DNaseI $\left(50 \mathrm{U} / \mathrm{ml}\right.$ for $30 \mathrm{~min}$ at $\left.37^{\circ} \mathrm{C}\right)$, and $(2)$ the vectors remained functional in vitro and in vivo. Thirty microliters $\left(\sim 5 \times 10^{9}\right.$ particles $)$ of each vector preparation were separated on a $10 \%$ SDS-PAGE gel and stained with Coomassie R250 to analyze the protein profile of the virions and to determine whether cellular contaminants were present. The presence of contaminating infectious Ad was determined by infecting $2 \times 10^{6} 293$ cells (these cells supply the Ad E1A gene products needed by Ad5 dl312) with $20 \mu$ l of the rAAV preparations and incubating the cells for $3 \mathrm{~d}$. No detectable cytopathic effect was present. The presence of contaminating wt-AAV was determined by a PCR assay. rAAV stock $(200 \mu \mathrm{l})$ was treated with DNaseI $(100 \mathrm{U} / \mathrm{ml}$ for $30 \mathrm{~min}$ at $37^{\circ} \mathrm{C}$ ) to degrade any unencapsidated DNA, treated with proteinase $\mathrm{K}$ $\left(0.5 \mathrm{mg} / \mathrm{ml}\right.$ for $60 \mathrm{~min}$ at $\left.37^{\circ} \mathrm{C}\right)$ to liberate the rAAV genomes, phenolextracted twice, ethanol-precipitated, and dissolved in $30 \mu \mathrm{l}$ of water, and $3 \mu \mathrm{l}$ was subjected to PCR along with positive and negative controls. The products were separated on a $2 \%$ agarose gel and stained with ethidium bromide; bands that were indicative of a wt-AAV contamination were not detected (Snyder et al., 1997).

A dot-blot assay was used to determine the total particle titer (Snyder et al., 1997) as follows. The rAAV stock was treated with DNaseI (50 $\mathrm{U} / \mathrm{ml}$ for $30 \mathrm{~min}$ at $37^{\circ} \mathrm{C}$ ) to degrade any unencapsidated DNA, treated with proteinase $\mathrm{K}\left(0.25 \mathrm{mg} / \mathrm{ml}\right.$ for $60 \mathrm{~min}$ at $\left.37^{\circ} \mathrm{C}\right)$ in the presence of $0.5 \%$ SDS and $10 \mathrm{~mm}$ EDTA to liberate the rAAV genomes, phenolextracted, ethanol-precipitated, denatured in alkali, and applied to a nylon membrane. Dilutions of the corresponding vector plasmid were used as standards to determine the rAAV virion copy number. A radioactive probe specific for the transgene was hybridized to the membrane, the filter was exposed to film, and the radioactive regions of the filter were excised and counted in a scintillation counter.

Functional rAAV titers were calculated by infecting $1 \times 10^{5} \mathrm{HeLa}$ or 293 cells with a dilution series of the rAAV stock in the presence of Ad (Ferrari et al., 1996). Cells were incubated for $48 \mathrm{hr}$, fixed, and stained for the presence of the transgene product. Immunostaining was performed using a monoclonal antibody against rat TH that cross-reacts to the human protein (Chemicon, Temecula, CA), followed by biotinylated goat anti-mouse (Vector Laboratories, Burlingame, CA) and a complex of streptavidin and biotin conjugated to HRP (Vector Laboratories). Diaminobenzidine was used for detection (Biogenix, San Ramon, CA). Positive cells were counted, and the titer was calculated from cell counts at rAAV dilutions where the infection rate is linear with dilution. Continued HeLa cell division during the $48 \mathrm{hr}$ interval was not taken into account in the estimation of functional vector titer. A comparison of the two titering methods reveals a total particle-to-infectious particle ratio of 100 - to 500 -fold. The precise characterization of particle number and functional titer are presented for the rAAV vectors used in this study in Table 1 .

Experimental subjects. Fischer 344 male rats weighing $220 \mathrm{gm}$ were obtained from Harlan Sprague Dawley (Indianapolis, IN), housed with access to ad libitum food and water on a $12 \mathrm{hr}$ light/dark cycle, and maintained and treated in accordance with published National Institutes of Health guidelines. All surgical procedures were performed with the rats under isofluorane gas anesthesia using aseptic procedures. After a rat was anesthetized in a "sleep box," it was placed in a small animal stereotaxic device (Kopf Instruments, Tujunga, CA) using the earbars that do not break the tympanic membrane. 


\begin{tabular}{lll}
\hline Table 1. Characterization of rAAV vectors & \\
rAAV vector description & $\begin{array}{l}\text { DNA titer } \\
\text { (particles/ml) }\end{array}$ & $\begin{array}{l}\text { Functional titer } \\
\text { (infectious units/ml) }\end{array}$ \\
\hline MD-TH & $1.0 \times 10^{11}$ & $3.6 \times 10^{9}$ \\
MD-GTPCHI & $1.0 \times 10^{11}$ & $3.0 \times 10^{9}$ \\
MD-AP & $6.2 \times 10^{12}$ & $1.0 \times 10^{8}$
\end{tabular}

Titers were determined as described in Materials and Methods.

6-OHDA lesions. Before any vector injections, unilateral 6-OHDA lesions were performed with the rats under isoflurane anesthesia by stereotaxic injection of $4 \mu \mathrm{g} / \mu \mathrm{l} 6-\mathrm{OHDA} \mathrm{HBr}$ (calculated as free base, dissolved in $2 \mathrm{mg} / \mathrm{ml}$ ascorbate-saline) at two separate sites (Schmidt et al., 1983). All animals used in this experiment were prescreened for robust amphetamine $(2.0 \mathrm{mg} / \mathrm{kg}, 1$ week after lesioning; mean total for rats in this experiment $=409 \pm 26 / 90 \mathrm{~min}$ ) and apomorphine-induced rotational behavior $(0.1 \mathrm{mg} / \mathrm{kg}$, three times beginning 3 weeks after 6-OHDA injection, once per week; mean total for rats in this experiment for the third test $=249 \pm 15 / 60 \mathrm{~min}$ ). This lesion has reliably led to a $>98 \%$ depletion of DA in the striatum in animals that met this screening criteria (S. Leff and R. Mandel, unpublished observations).

Rotational behavior was assessed using automated rotometers (Ungerstedt and Arbuthnott, 1970). The rats were placed in the apparatus and allowed to habituate for between 5 and 10 min After the habituation period, each rat was injected with the appropriate agonist. Net rotations were calculated as rotations in the inappropriate direction subtracted from rotations in the appropriate direction (clockwise for apomorphineinduced rotational behavior, counterclockwise for amphetamine-induced rotational behavior).

Intracerebral injection of $r A A V$ vectors. After the rats were placed in the stereotaxic frame, rAAV in PBS was injected into the striatum [anteroposterior (AP) $0.0 \mathrm{~mm}$, lateral (LAT) $3.0 \mathrm{~mm}$, dorsoventral (DV) -5.5 , $-4.5,-3.5 \mathrm{~mm}$, with the incisor bar set at $-3.3 \mathrm{~mm}$ below the intra-aural line (Paxinos and Watson, 1987)] through a $5 \mu \mathrm{l}$ Hamilton syringe fitted with a 30 gauge beveled hypodermic needle over $1 \mathrm{~min}$ at a rate of 1 $\mu \mathrm{l} / \mathrm{min}$. The rate of injection was precisely controlled by an infusion pump (Razel Scientific Instruments, Stamford, CT) that pushed a piston that in turn depressed the plunger on the Hamilton syringe. During the injection the needle was slowly raised $1 \mathrm{~mm}$ in the dorsal direction every $20 \mathrm{sec}$. One minute after the cessation of the injection, the needle was retracted an additional $1 \mathrm{~mm}$ and then left in place for an additional 4 min before being slowly withdrawn from the brain. Forty unilateral 6-OHDA-lesioned animals were divided into four separate experimental groups statistically balanced for equality of prevector injection amphetamine- and apomorphine-induced rotational behavior. Each group was randomly assigned to receive one of the following $1 \mu \mathrm{l}$ intrastriatal vector injections as described above: rAAV-MD-hTH; rAAV-MD-GTPCHI; a 1:1 mixture of rAAV-MD-hTH and rAAVMD-GTPCHI; and $1 \mu \mathrm{l}$ PBS injections served as the control condition. Three weeks after rAAV injection, two to six animals from each group were killed and their brains were processed for immunocytochemistry. Six months after intrastriatal rAAV injection, the remaining 4-10 animals per group were killed and processed identically to the previous animals.

A total of 48 unilateral 6-OHDA-lesioned animals, which underwent the microdialysis procedure or were used to determine neuronal versus astrocytic specificity of expression, received $4 \times 1 \mu \mathrm{l}$ intrastriatal injections [(1) AP $+0.5 \mathrm{~mm}$, LAT $-3.0 \mathrm{~mm}, \mathrm{DV}-5.5,-4.5,-3.5 \mathrm{~mm}$; (2) AP $0.0 \mathrm{~mm}$, LAT $-2.7 \mathrm{~mm}, \mathrm{DV}-5.5 \mathrm{~mm},-4.5,-3.5 \mathrm{~mm}$; (3) AP 0.0 $\mathrm{mm}$, LAT $-3.2 \mathrm{~mm}$, DV $-5.5,-4.5,-3.5 \mathrm{~mm}$; (4) AP $-0.7 \mathrm{~mm}$, LAT $-3.0 \mathrm{~mm}, \mathrm{DV}-5.5,-4.5,-3.5 \mathrm{~mm}]$ where each individual injection was identical to the single injections described above. Thirty-two lesioned rats were divided into four experimental groups that were balanced according to amphetamine- and apomorphine-induced rotational behavior before vector infection. The groups were randomly assigned to one of the following vector injection regimens: rAAV-MD-hTH; rAAV-MDGTPCHI; a 1:1 mixture of rAAV-MD-hTH and rAAV-MD-GTPCHI; and rAAV-MD-hAP to control for infection. The remaining 16 6-OHDA-lesioned rats were divided into the same behaviorally balanced groups as above but only seven of those vector-injected rats that received the following vector injections were used in the cell identification portion of this experiment: rAAV-MD-hTH or a 1:1 mixture of rAAV-MD-
hTH and rAAV-MD-hGTPCHI. The final individual "n" numbers for each vector injection group in the microdialysis experiments and in the cell identification experiment are noted in their respective graph or Table in the Results section.

A different set of three unilaterally 6-OHDA-lesioned rats with partial striatal DA denervations (mean amphetamine rotations $=388 \pm 148$; mean apomorphine-induced rotations $=114 \pm 48$ ) received $2 \times 1 \mu \mathrm{l}$ injections of rAAV-MD-hTH $(n=3)$ as described above and were allowed to live 1 year before they were killed. Their brains were processed for $\mathrm{TH}$ immunocytochemisty.

Microdialysis. The dialysis probes used in the present experiment were of the concentric type (0.5 mm diameter; Carnegie Medicin, CMA12) with a molecular weight cutoff for influx of $20 \mathrm{kDa}$. All the microdialysis probes had $4 \mathrm{~mm}$ of exposed dialysis membrane. The probes were tested for their recovery rate for L-DOPA, which was determined to be an average of $19.9 \%$ and did not vary significantly among groups $\left(F_{(4,27)}=\right.$ $0.6 ; p>0.6)$. The reported HPLC-determined L-DOPA and L-dihydroxyphenyl acetic acid (DOPAC) values have not been corrected for recovery percentages.

The probes were implanted with the rats under isofluorane anesthesia at the following coordinates: $+0.0 \mathrm{~mm}$ anterior, $-3.0 \mathrm{~mm}$ lateral to bregma, and $-5.5 \mathrm{~mm}$ ventral from dura, with the incisor bar set at -3.3 $\mathrm{mm}$ below the intra-aural line.

Microdialysis experiments were performed as described (Leff et al., 1998). The first microdialysis experiment was designed to examine the $\mathrm{BH}_{4}$ dependence of the L-DOPA production from rAAV-infected DAdepleted striata. The microdialysis regimen consisted of five consecutive baseline samples in which Ringer's solution was passed through the probes. Beginning with the start of the sixth sampling period, $200 \mu \mathrm{M}$ $\mathrm{BH}_{4}$ (Research Biochemicals, Natick MA) was added to the Ringer's solution and perfused through the probes for the next $2.5 \mathrm{hr}(10 \mathrm{sam}-$ ples); $1.25 \mathrm{hr}$ (five samples) after the start of the $\mathrm{BH}_{4}$ perfusion, 50 $\mathrm{mg} / \mathrm{kg}$ of the central L-aromatic amino acid decarboxylase (AADC) inhibitor, NSD-1015 (RBI), was injected intraperitoneally in each animal; and $1.25 \mathrm{hr}$ later (five samples) the intraprobe perfusion of $\mathrm{BH}_{4}$ was discontinued and replaced with the Ringer's solution for 45 min (three samples). The animals were allowed to awaken and then placed back in their holding buckets for 12-18 hr overnight.

The second day of microdialysis was designed to determine whether the L-DOPA detected in rAAV-TH-infected animals was released via a depolarization-dependent mechanism. This second microdialysis session was identical to the first session except that at the start of the third sample $100 \mathrm{~mm} \mathrm{KCl}$ was added to the Ringer's solution (in addition, all the $\mathrm{NaC}$ was removed from the Ringer's solution in an attempt to keep the osmolarity of the solution as stable as possible), and the $\mathrm{KCl}$ was removed at the end of the $15 \mathrm{~min}$ sampling period. As in the first microdialysis session, at the start of the sixth sample, $\mathrm{BH}_{4}$ was added to the Ringer's solution that was being perfused through the probes. Fortyfive minutes later, another one-sample $100 \mathrm{~mm} \mathrm{KCl}$ depolarization stimulus was performed, and the experiment was ended 45 min later. These animals were then systemically injected with NSD-1015 and killed 1.5-2.0 hr later. In addition to the animals in this microdialysis experiment, three previously naive unlesioned rats were implanted with unilateral dialysis probes as described above and underwent an experiment in which after three baseline microdialysis samples were collected, an intraprobe $100 \mathrm{~mm} \mathrm{KCl}$ perfusion was performed and the dialysate was analyzed for DA to demonstrate the efficacy of this $\mathrm{KCl}$ regimen (Kalén et al., 1988; Mandel et al., 1994).

At the time the animals were killed, their brains were placed in $4^{\circ} \mathrm{C}$ PBS for several minutes and then placed in a Kopf rat brain tissue slicing apparatus, and a $3 \mathrm{~mm}$ coronal slice of striatum was removed in the area of the dialysis probe implantation. Tissue punches $(2 \times 2 \mathrm{~mm}$ diameter $)$ were then taken from the dorsal and ventral portions of the injection tract.

HPLC. The levels of L-DOPA, DA, and DOPAC in $20 \mu \mathrm{l}$ samples were analyzed by reverse-phase HPLC using a C-18, $3 \times 150 \mathrm{~mm}$ Hypersil ODS (Keystone Scientific) column and an ESA Coulochem II electrochemical detector (Leff et al., 1998). This HPLC assay is optimized for the detection of L-DOPA. The peak for DA appears just after the DOPAC peak in this method. Therefore, DA quantification from dialysates was not possible for all samples; however, DOPAC determinations were reliable. Therefore, the DOPAC data are presented as an indicator of the presence of DA because metabolism of striatal DA leads to the formation of DOPAC

Immunoblotting. Brain punches $(\sim 10 \mathrm{mg}$ wet weight $)$ were homoge- 
nized by sonication (Branson Sonifier 250; output setting 2, 20\% duty cycle $\times 5-10 \mathrm{sec})$ in $15 \mathrm{vol}$ of ice-cold homogenization buffer, and a portion of the samples was diluted 1:1 in $2 \times$ Tris-glycine SDS sample buffer. Immunoblots were performed as described previously (Leff et al., 1998) using a 1:1000 dilution of a monoclonal anti-rat $\mathrm{TH}$ antibody (MAB 318, Chemicon).

Antisera against human GTPCHI. Antibodies against hGTPCHI were raised in rabbits using a synthetic 12 amino acid (GFPERDPPRPGP, aa 21-32) peptide conjugated to $\mathrm{KLH}$ as antigen. Injection schedule, site, and adjuvant were as described previously (Hurn and Chantler, 1980; Sigel et al., 1983). Sera reactive against immunizing antigen and expressed hGTPCHI was observed at the first production bleed and through three additional boosts over $94 \mathrm{~d}$. IgG was purified using protein A Sepharose affinity chromatography. The specificity of the GTPCHI antibody was confirmed by an immunoblot experiment using rAAVMD-hGTPCHI-transduced HeLa cells. rAAV-MD-hGTPCHItransduced HeLa cells but not nontransduced HeLa cells or rAAV-MDhTH2-transduced HeLa cells showed a positive band at the predicted molecular weight of the hGTPCHI monomer $(\sim 29 \mathrm{kDa})$.

Histology. Each animal was deeply anesthetized with intraperitoneal pentobarbital and perfused through the aorta with sterile PBS, followed by ice-cold $4 \%$ paraformaldehyde (PFA) perfusion. The brains were removed from the skull, post-fixed in 4\% PFA by immersion for $24 \mathrm{hr}$, and then transferred into a 30\% sucrose/PBS solution for 3-4 d until the brains sank to the bottom of their containers. The brains were then frozen on dry ice, and $40-\mu \mathrm{m}$-thick coronal sections were cut on a sliding microtome. Sections were collected in microtiter-well plates in series that contained a glycerin-based antifreeze solution, and they were kept at $-30^{\circ} \mathrm{C}$ until further processing.

Immunocytochemistry was performed following the general procedure described previously (Sternberger et al., 1970). After several PBS rinses and an incubation in $3 \%$ hydrogen peroxide, the sections were placed in a $3 \%$ normal serum from the species in which the primary antibody was raised [i.e., normal horse serum for $\mathrm{TH}$ and normal goat serum for GTPCHI (Vector Laboratories) for $30 \mathrm{~min}$ to block nonspecific antigens]. The blocking step was followed by the primary antibody incubation, which varied depending on the primary antibody. TH staining was performed using a monoclonal anti-TH antibody (diluted in PBS with $1 \%$ NHS and $0.1 \%$ Triton X-100 in 1:1000 dilution) for $18 \mathrm{hr}$ at room temperature. The coronal sections were then washed in PBS and mounted on glass slides. Immunocytochemical staining for GTPCHI was performed similarly to that described for $\mathrm{TH}$, except that sections were incubated with GTPCHI primary antibody (1:1000) only briefly (1-5 min).

To study the identity of the rAAV infected cells that were expressing $\mathrm{TH}$, brain tissue was double-labeled with an anti-TH monoclonal antibody in combination with either a monoclonal antibody against the neuron-specific nuclear antigen NeuN (Mullen et al., 1992) or GFAP (Chemicon). Free-floating coronal sections were incubated in anti-TH antibody at a 1:1000 dilution overnight at room temperature. This was followed by an overnight incubation with a 1:100 dilution of NeuN antibody at room temperature and processed for fluorescent detection with the enzyme-linked fluorescence (ELF)-AP immunohistochemistry kit (Molecular Probes, Eugene, OR), according to the method of Larison et al. (1995).

Determination of cell numbers. Cell counting was performed by observers who were blinded with respect to experimental group or survival time of any subject. Tissue sections were made in the coronal plane, and all of the $\mathrm{TH}^{+}$cells in a particular striatal section were counted by two independent observers. Cells were counted as $\mathrm{TH}^{+}$if the object to be counted had darker chromagen staining than the surrounding background and could be clearly identified as a cell with at least one process. Therefore, small $(<10 \mu \mathrm{m})$ round dark "spots" that may have been the proximal end of a cell were not counted. Total cell numbers were calculated by first determining the most anterior and posterior extent of the lesion and calculating the total length of the infected area by multiplying the number of sections that contained TH-expressing cells by 40 $\mu \mathrm{m}$. The sections counted were at least $480 \mu \mathrm{m}$ apart. The average number of $\mathrm{TH}^{+}$cells per section was then corrected using the method of Abercrombie (1946). The corrected cell counts were then multiplied by the length of the infected site to calculate the total cell number. This method was followed for each animal before revealing to which experimental group an animal belonged. Because the calculations of cell counts do not conform to current unbiased stereological methods (Gundersen et al., 1988a,b), these counts do not represent actual infected cell numbers but are sufficient to be used for relative comparisons.

Statistics. Factorial ANOVA was used to determine the probability of significant differences (a level was $p<0.05$ ). Statistical analysis microdialysis experiments were performed using repeated-measures ANOVA. A hierarchical approach to simple main effects for post hoc analyses as described by Kirk (1968) was followed. If significant time sample $\times$ group interactions were encountered, individual group differences at particular time points were tested where appropriate.

\section{RESULTS}

\section{Persistence of rAAV-mediated hTH and hGTPCHI gene expression}

To determine the persistence of striatal gene expression after rAAV delivery, rAAV-hTH and rAAV-hGTPCHI vectors were injected, and histological analyses were performed (Figs. 1-3). Both hTH expression (Figs. 1, 3A-D) and hGTPCHI expression (Fig. 2E,F) were present at 3 weeks and 6 months after rAAV injection. Representative examples of TH staining of rAAVMD-hTH-transduced tissue (Fig. 1), GTPCHI staining of rAAV-MD-hGTPCHI-transduced striatal tissue (Fig. $2 E, F$ ), and TH staining of control tissues [PBS injections (Fig. $2 A, B$ ) and rAAV-MD-hGTPCHI injections (Fig. $2 C, D$ )] 3 weeks after surgery show that minimal tissue disruption occurred in both PBS injection and vector injections. Examination of the morphology of both hTH expressing cells and those expressing hGTPCHI suggested that these cells were predominantly neurons.

The sections taken from the rAAV-transduced animals that survived for 3 weeks were stained with hematoxylin and eosin and examined for histopathology (data not shown). Although there was clear evidence of the presence of a needle tract that contained hemosiderin in most cases, there was no mononuclear cell infiltrate or cuffing of nearby blood vessels.

Cell counts were performed on TH-stained tissue sections processed at 3 weeks $(n=6)$ and 6 months $(n=9)$ after infection, and the estimated cell numbers for each rAAV-hTH transduced animal are presented in Figure 4. The cell count data indicate a fourfold drop in the number of cells expressing the hTH transgene between 3 weeks and 6 months $\left(F_{(1,13)}=4.7 ; p=0.05\right)$, similar to declines that have been reported previously for other types of viral vectors that use the CMV promoter (Guo et al., 1996; Neve and Geller, 1996). Nevertheless, the estimated $\mathrm{TH}^{+}$ cell numbers remain in the 400-2000 range at 6 months after injection of only $1 \mu \mathrm{l}$ of vector, which is still relatively significant transgene expression compared with the number of $\mathrm{TH}^{+}$cells necessary for functional effects in a fetal ventral mesencephalic transplantation setting (Brundin et al., 1988). Several TH-stained sections from animals that received PBS or rAAV-MD-hGTP$\mathrm{CHI}$ were examined and revealed no striatal $\mathrm{TH}^{+}$cells on the lesioned side (data not shown).

A separate group of partially 6-OHDA-lesioned rAAV-MDhTH-injected animals $(n=3)$ were allowed to survive for 1 year. Remaining $\mathrm{TH}^{+}$fibers are clearly evident in the medial striatum (Fig. 5), indicative of the partial nature of the striatal DA depletion in these animals. TH immunocytochemical staining was present in striatal cell bodies to a variable degree in all three animals. Because $\mathrm{TH}^{+}$neurons are not normally found in the rat striatum, the presence of $\mathrm{TH}^{+}$cell bodies can only be attributed to continued transgene expression 1 year after rAAV injection (Fig. 5). Quantitative comparison of the hTH expression seen at 6 months (Fig. 3) and 1 year (Fig. 5) was not made, because these two time points were taken from animals used in separate experiments. Furthermore, the animals that survived for 6 months 

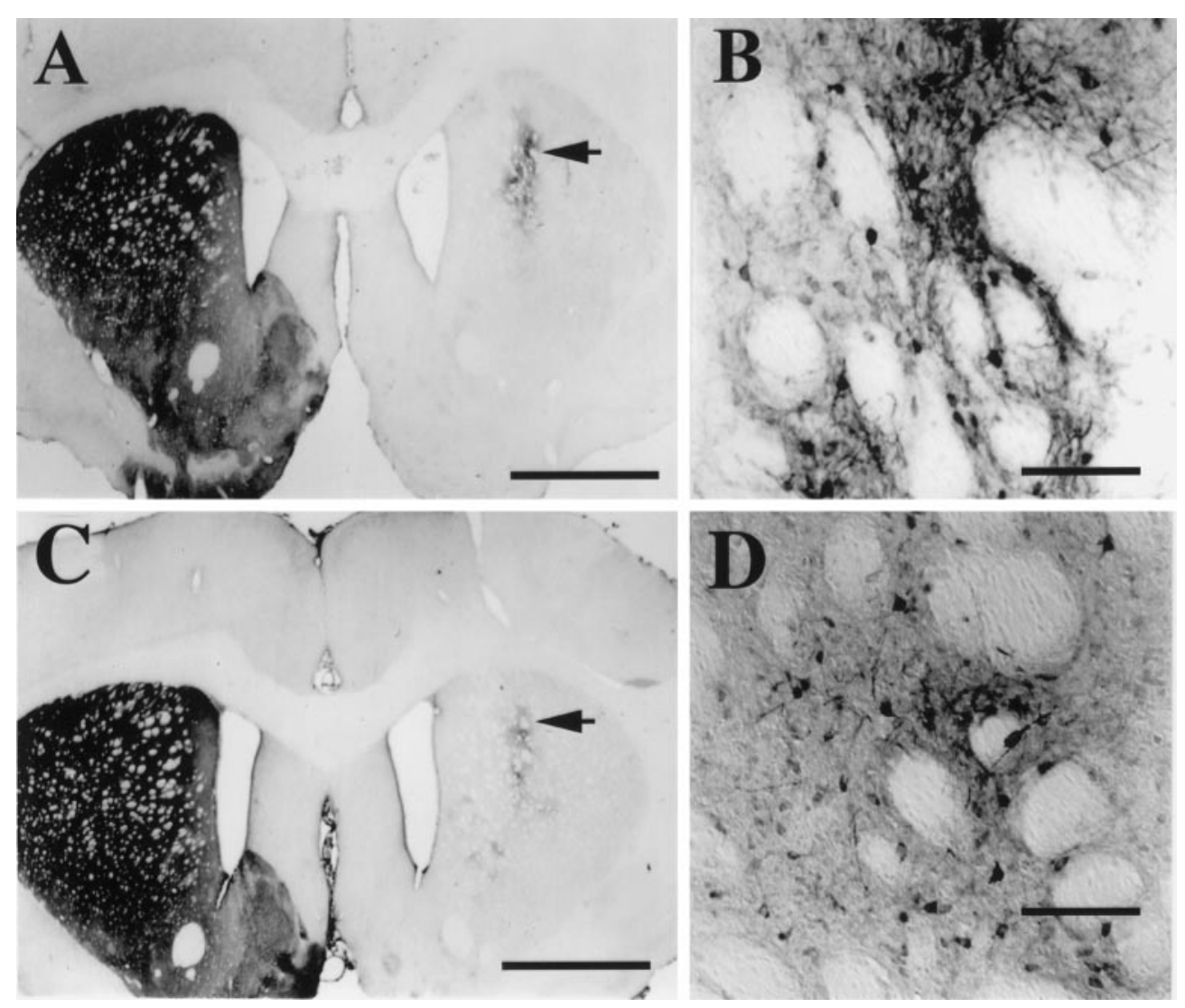

Figure 1. TH immunocytochemical staining 3 weeks after rAAV infection. The low magnification in $A$ and $C$ show the spread of infection relative to the size of the entire striatum. Intense TH staining is apparent in the left hemisphere relative to the right hemisphere because the animals received a unilateral 6-OHDA lesion to deplete the background TH in the right hemisphere. $B$ and $D$ contain higher-power magnifications of field present in $A$ and $C$. The area of enlargement presented in $B$ and $D$ are indicated by the arrows in $A$ and $C$. Because the injection needle was withdrawn $3 \mathrm{~mm}$ during surgery, the dorsoventral extent of the area of transgene expression is $3-4 \mathrm{~mm}$ in all examples. $\mathrm{TH}^{+}$cells that delineate the area of infection had a medial-lateral extent of $\sim 0.7 \mathrm{~mm}$ and a $1.2 \mathrm{~mm}$ anterior-posterior spread. $A$ and $B$ and $C$ and $D$ contain views of the neostriatum after infection with $1 \mu \mathrm{l}$ with rAAV-MD-hTH and a 1:1 mixture of rAAV-MD-hTH and rAAV-MD-hGTPCHI in the TH-depleted hemisphere at 3 weeks after infection, respectively. In $B$ there is a small amount of hemosiderin present in the lower portion of this field, indicating that this precise area of the injection shows little disruption of the tissue in this area. Although only half the rAAV-MD-hTH vector $(0.5 \mu \mathrm{l})$ was injected in these animals, the intensity of TH staining was still comparable to the undiluted vector injection $(A$ and $B$ ) (also see Fig. 4). Scale bars: $A, C, 2 \mathrm{~mm} ; B, D$, $100 \mu \mathrm{M}$. received $1 \mu \mathrm{l}$ of vector, and the animals that survived for 1 year received $2 \mu \mathrm{l}$ of vector.

\section{Neuronal specificity of rAAV-mediated gene expression}

To quantify the proportion of transgene-expressing cells that are neurons, striatal sections from rAAV-hTH-transduced animals were processed for a double-staining procedure in which hTH was detected immunocytochemically with a light-microscopic chromagen (VIP, Vector Laboratories), and NeuN, a neuronal specific marker, was detected immunocytochemically using ELF, a fluorescent chromagen. Because of the extreme intensity of the ELF chromagen, both low-level visible light and fluorescent light could be projected through the section simultaneously, allowing identification of double-stained cells for counting (Fig. 6A). The data from the $\mathrm{TH}-\mathrm{NeuN}$ double-staining studies are presented in Table 2. These data indicate that the vast majority $(>90 \%)$ of the striatal cells that express the hTH transgene are neurons.

To investigate the identity of the small percentage of cells that were $\mathrm{TH}$ immunopositive but NeuN negative, a similar lightfluorescent double-staining study was used where the GFAP, an astrocytic marker, was substituted for the NeuN neuronal marker. Figure $6 B$ shows a photomicrograph of an example of a $\mathrm{TH}$ (visible light chromagen)-GFAP (fluorescent chromagen) double-stained striatal section. The data from cell counts of $\mathrm{TH}^{+}$ cells, and the percentage of which are double-stained for GFAP, are presented in Table 2 . These data indicate that $<1 \%$ of the striatal cells that express the hTH transgene are astrocytes, and given the possibility of detecting false positives using this technique, this small proportion of expressing astrocytes should not be considered significant.

\section{Apomorphine-induced rotational behavior}

Just before the initiation of the microdialysis experiments, the rats that were to be evaluated for either cell specificity of expression or L-DOPA production by microdialysis underwent a postinfection apomorphine-induced rotational behavior session $(n=12$ per group) (Fig. 7). Although there was a slight overall reduction of apomorphine-induced rotations $(-20 \%)$ across all groups (before rotation vs after rotation, $\left.F_{(1,44)}=5.1 ; p=0.03\right)$, there was no significant difference between the groups either before or after infections with rAAV (main effect of group, $F_{(3,44)}=0.1 ; p>$ $0.95)$, nor did any individual group show a postinfection reduction of rotational behavior (group $\mathrm{X}$ preinfection/postinfection interaction, $\left.F_{(3,44)}=1.1 ; p=0.35\right)$. These same animals were used in the histological analysis of cell specificity (described above) or the microdialysis experiments (described below).

\section{rAAV-MD-hTH-mediated L-DOPA production}

The results of the microdialysis experiments are presented in Figures 8 and 9. The first experiment (Fig. 8) investigated whether AAV-mediated excess striatal L-DOPA could be measured in the dialysate in the presence or absence of exogenous $\mathrm{BH}_{4}$. To enhance the probability of measuring any transgenically produced L-DOPA, CNS AADC activity was blocked with NSD1015 halfway through the $\mathrm{BH}_{4}$ infusion. The data from this experiment show that only the group of rats that received a $1: 1$ mixture of the rAAV-MD-hTH and rAAV-MD-hGTPCHI vectors produced measurable L-DOPA levels before the addition of exogenous $\mathrm{BH}_{4}$ (first $1.25 \mathrm{hr}$ ) (Fig. $8 \mathrm{~A}$ ). After the beginning of the $\mathrm{BH}_{4}$ infusion $(200 \mu \mathrm{M})$, the rAAV-MD-hTH-transduced 

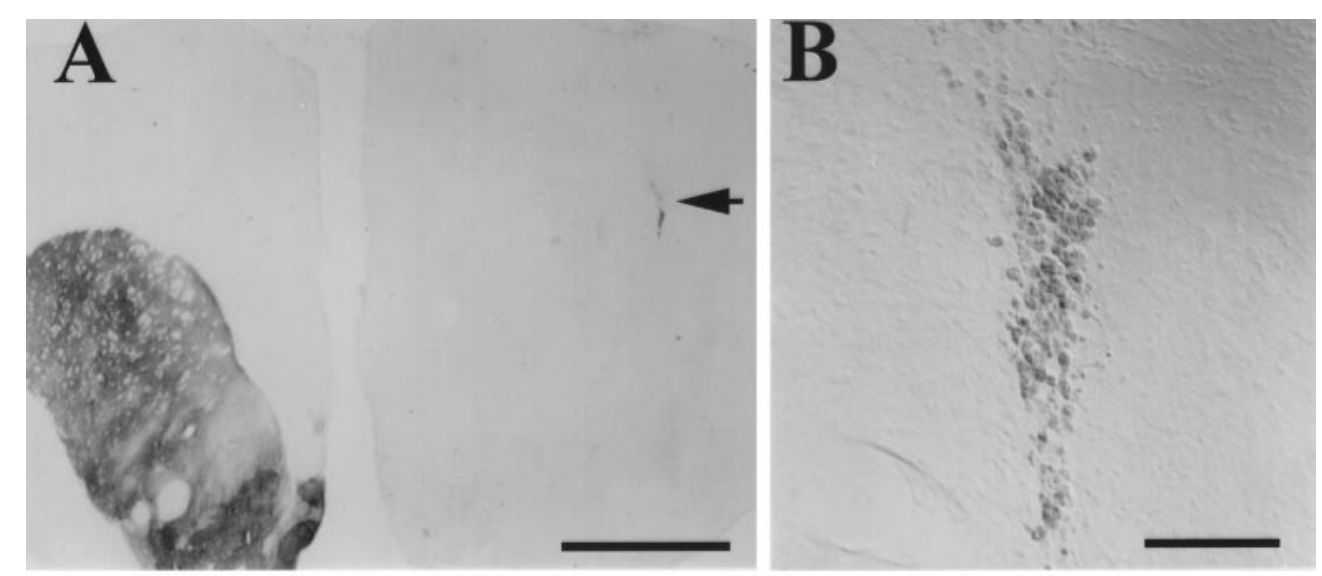

Figure 2. Striatal TH immunocytochemical stain of $1 \mu \mathrm{l}$ PBS and rAAVMD-hGTPCHI infections 3 weeks after injection $(A-D)$ and GTPCHI staining of rAAV-hGTPCHI-infected striatum 3 weeks after injection $(E, F)$. $A$ depicts a low-magnification view of $\mathrm{TH}$ staining of a coronal brain section from an animal that received a $1 \mu \mathrm{l}$ PBS injection in the 6-OHDA-lesioned striatum. The injection site is clearly visible in the dorsal striatum. $B$ shows the higher magnification of the site of the PBS injection, which still contains residual hemosiderin 3 weeks after injection. $C$ contains a low magnification of $\mathrm{TH}$ staining of a striatum from an animal that received a $1 \mu \mathrm{l}$ injection of rAAVMD-hGTPCHI 3 weeks earlier. $D$ shows the high magnification of this same area. $E$ and $F$ show low- and highpower magnification of hGTPCHI immunocytochemical staining from an animal that received $\mathrm{rAAV}-\mathrm{MD}$ hGTPCHI 3 weeks before histological processing. The GTPCHI antibody was raised against the human protein and does not cross-react with the rat GTP$\mathrm{CHI}$ present in the intact hemisphere. The area of enlargement presented in $B$, $D$, and $F$ are indicated by the arrows in $A, C$, and $E$. Scale bars: $A, C, F, 2 \mathrm{~mm} ; B$, $D, E, 100 \mu \mathrm{M}$.
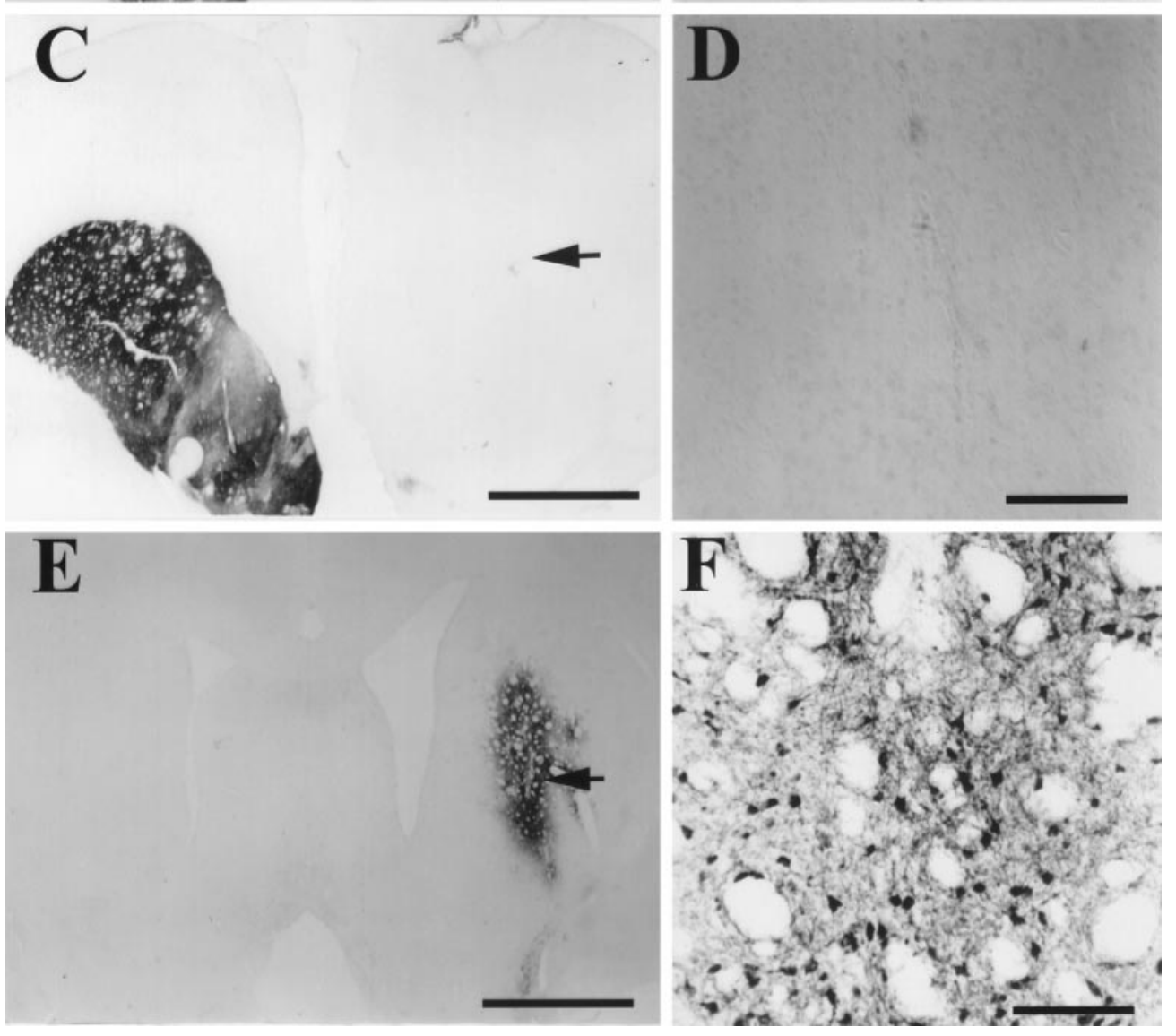

group began to yield measurable L-DOPA levels. Although there was a highly significant difference in measured L-DOPA levels between the groups $\left(F_{(3,23)}=4.4 ; p<0.01\right)$, this effect was completely attributable to the fact that the 1:1 rAAV-MD-hTH and rAAV-MD-hGTPCHI mixture group showed significantly greater L-DOPA levels than all other groups (simple main effects, $p<0.05$ for each contrast). Addition of $\mathrm{BH}_{4}$ to the dialysate did not significantly enhance the L-DOPA levels of the 1:1 rAAVMD-hTH and rAAV-MD-hGTPCHI mixture group $\left(F_{(1,23)}=\right.$ 1.6; $p>0.1)$, but the additional injection of NSD-1015 that blocked CNS AADC activity did significantly enhance this group's L-DOPA levels relative to the previous samples $\left(F_{(1,23)}=\right.$ $7.4 ; p=0.01$ ). As was the case with the L-DOPA levels, the group injected with the 1:1 rAAV-MD-hTH and rAAV-MD-hGTPCHI mixture displayed significantly elevated levels of the DA metabolite, DOPAC, as compared with the rAAV-MD-hAP- and the rAAV-MD-hGTPCHI-injected control groups $\left(F_{(1,23)}=\right.$ $13.9, p<0.001 ; F_{(1,23)}=11.4, p=0.001$, respectively) (Fig. $8 B$ ). These levels of DOPAC suggested that higher levels of striatal DA turnover were present in the animals. As might be expected, the injection of NSD-1015 significantly blocked the DOPAC measured in the 1:1 rAAV-MD-hTH and rAAV-MD-hGTPCHI mixture injected group (comparison of the first nine samples vs the nine samples after the NSD-1015 injection: $F_{(1,23)}=13.1 ; p<$ $0.001)$. No other rAAV-injected group displayed significant DOPAC levels in their dialysates $(p>0.5)$. However, in some treatment groups other than the mixed rAAV-MD-hTH and rAAV-hGTPCHI group, very low pre- $\mathrm{BH}_{4}$ DOPAC levels were observable, but these levels were probably an index of the 6-OHDA lesion severity and not related to transgene expression.

The second microdialysis experiment (Fig. 9), performed $24 \mathrm{hr}$ later, was designed to determine whether the rAAV infection- 

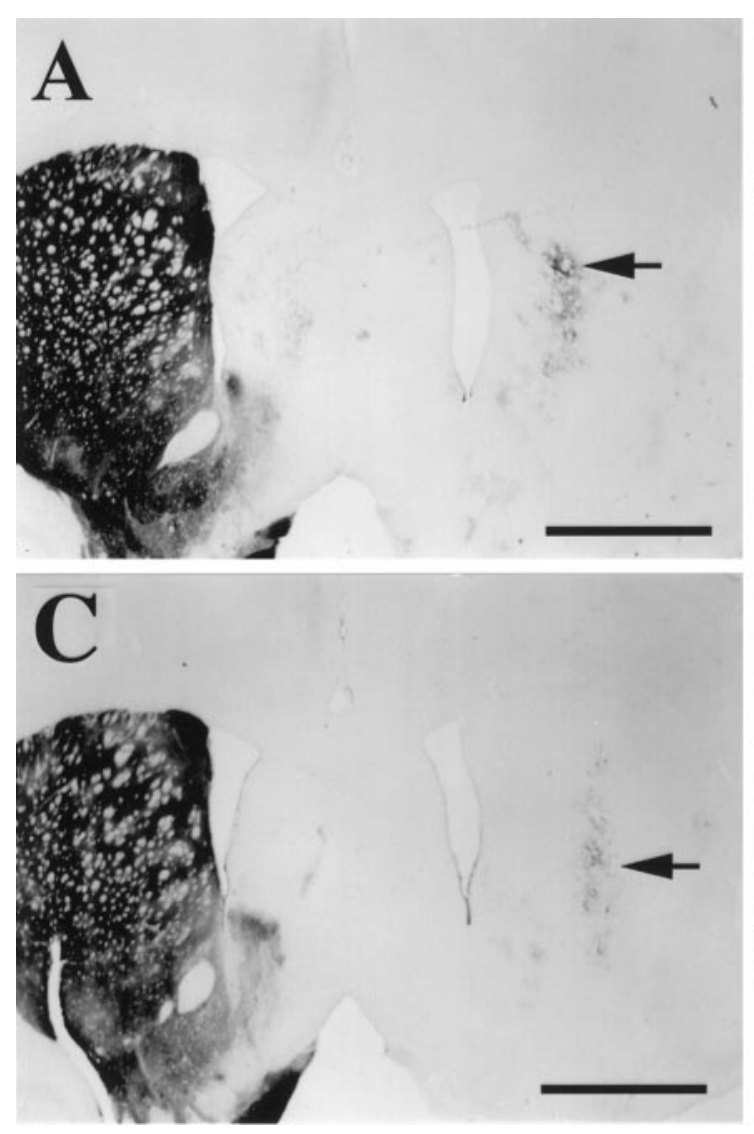

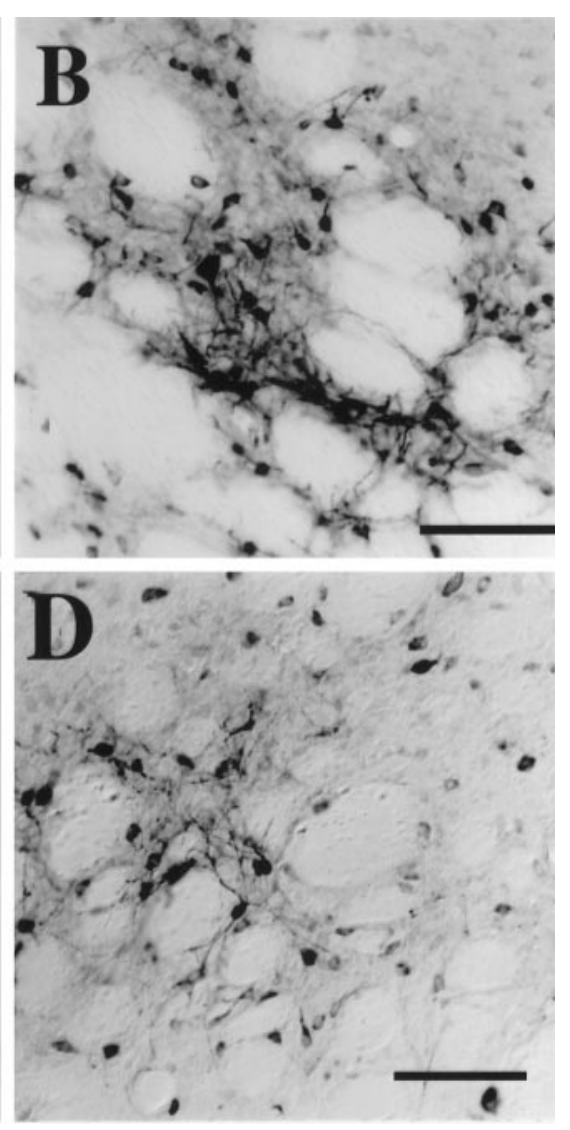

Figure 3. TH staining of rAAVinfected striatum 6 months after vector injection. The figure shown is arranged identically to Figure 1, where the panel on the right contains a higher magnification of a field within the rAAV-infected area of the panel on the left. The histology presented in this figure comes from the animals that were prepared in the same surgical session as those presented in Figure 1. $A$ and $C$ contain lowmagnification photomicrographs of coronal sections from unilateral 6-OHDA-lesioned rats 6 months after a $1 \mu \mathrm{lAAV}$ injection in each lesioned animal. The low magnifications show the extent of the area of infection. The areas of enlargement presented in $B$ and $D$ are indicated by the arrows in $A$ and $C$. $A$ and $B$ contain pictures from a representative sample from an animal infected with rAAV-MD-hTH (compare Fig. 1, $A$ and $B) . C$ and $D$ contain an example of an animal that received the 1:1 mixture of rAAV-MD-hGTPCHI and rAAV-MD-hTH. Scale bars: $A, C, 2$ $\mathrm{mm} ; B, D, 100 \mu \mathrm{M}$. mediated striatal L-DOPA levels would respond to a stimulus that depolarizes neurons in the area of the dialysis probe $(100 \mathrm{~mm}$ $\mathrm{KCl}$ ). These measurements were also made in the presence or absence of exogenous $\mathrm{BH}_{4}$. Similar to the first microdialysis experiment, only the group of rats transduced with the 1:1 mixture of rAAV-MD-hTH and rAAV-MD-hGTPCHI displayed measurable L-DOPA before the infusion of $\mathrm{BH}_{4}$ (Fig. 9A). The animals that received the intrastriatal injection of the rAAV mixture showed significantly more L-DOPA release than all the other experimental groups $\left(F_{(1,21)}=9.9 ; p=0.005\right) . \mathrm{BH}_{4}$ infusion enhanced the levels of L-DOPA measured from the animals that received the vector mixture, and four of six rats that received rAAV-MD-hTH displayed consistently detectable L-DOPA levels after $\mathrm{BH}_{4}$ infusion. Inf usion of $100 \mathrm{~mm} \mathrm{KCl}$ for $15 \mathrm{~min}$ before $\mathrm{BH}_{4}$ inf usion (sample 3) and after $\mathrm{BH}_{4}$ inf usion (sample 10) had no effect on the L-DOPA levels ( $p>0.05$; the comparisons were made independently for the pre- $\mathrm{BH}_{4}$ samples and the post- $\mathrm{BH}_{4}$ samples). The inset in Figure $9 A$ presents the mean DA $(+\mathrm{SEM})$ measured from three untreated rats. Sixty minutes after the start of the experiment, $100 \mathrm{~mm} \mathrm{KCl}$ was added to the dialysate for 15 min and then removed. The inset shows that the $\mathrm{KCl}$ regimen used in this experiment does lead to a local depolarization that causes increased neurotransmitter release. These data show clearly that the $100 \mathrm{~mm} \mathrm{KCl}$ induced a marked release of DA only in the sample containing the high potassium concentration. Figure $9 B$ contains the mean levels of DOPAC $(+$ SEM) measured from the same dialysate samples as reported in Figure $9 A$. Animals injected with the 1:1 mixture of rAAV-MD-hTH and rAAV-MD-hGTPCHI intrastriatally displayed significantly elevated striatal DOPAC levels as compared with all other rAAVinjected groups $\left(F_{(1,21)}=24.1 ; p<0.001\right)$. Although the same animals from the rAAV-MD-hTH-injected group that displayed measurable L-DOPA levels (Fig. 9A) also displayed measurable DOPAC levels, these levels were not significantly different from the rAAV-MD-hGTPCHI- and rAAV-MD-hAP-injected control groups $\left(F_{(1,21)}=0.5 ; p>0.6\right)$. Addition of $100 \mathrm{~mm} \mathrm{KCl} \mathrm{had}$ no effect on the measured DOPAC in any of the vector-injected

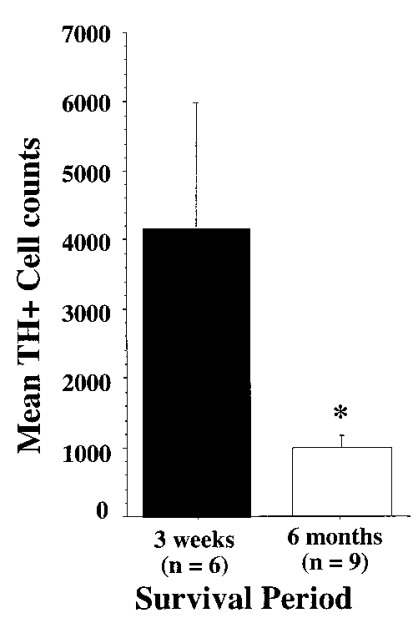

Figure 4. Striatal $\mathrm{TH}^{+}$cell counts taken from animals infected with rAAV-MD-hTH 3 weeks and 6 months previously. The mean Abercrombie corrected $\mathrm{TH}^{+}$cell counts $(+\mathrm{SEM})$ from animals processed 3 weeks after transduction with rAAV-MD-TH is represented by the black bar, and the mean corrected cell counts from rAAV-transduced animals allowed to survive 6 months is represented by the open bar. The asterisk indicates a significant reduction of the number of $\mathrm{TH}^{+}$cells at 6 months $(p=0.05)$. 
Figure 5. TH staining of rAAV-MDhTH-infected striatum 1 year after vector injection. This figure is arranged identically to Figures 1 and 3, where the panel on the right contains a higher magnification of a field within the rAAV-infected area of the panel on the left. The area of enlargement presented in $B$ is indicated by the arrow in $A$. The histology presented in this figure comes from a separate group of partially 6-OHDA-lesioned rats that received rAAV-MD-hTH 1 year previously. The level of transgene expression observed in these animals cannot be directly compared with that presented in Figures 1 and 3 because the animals shown here did not receive identical surgeries. Scale bars: $A, 2 \mathrm{~mm} ; B, 100 \mu \mathrm{M}$.
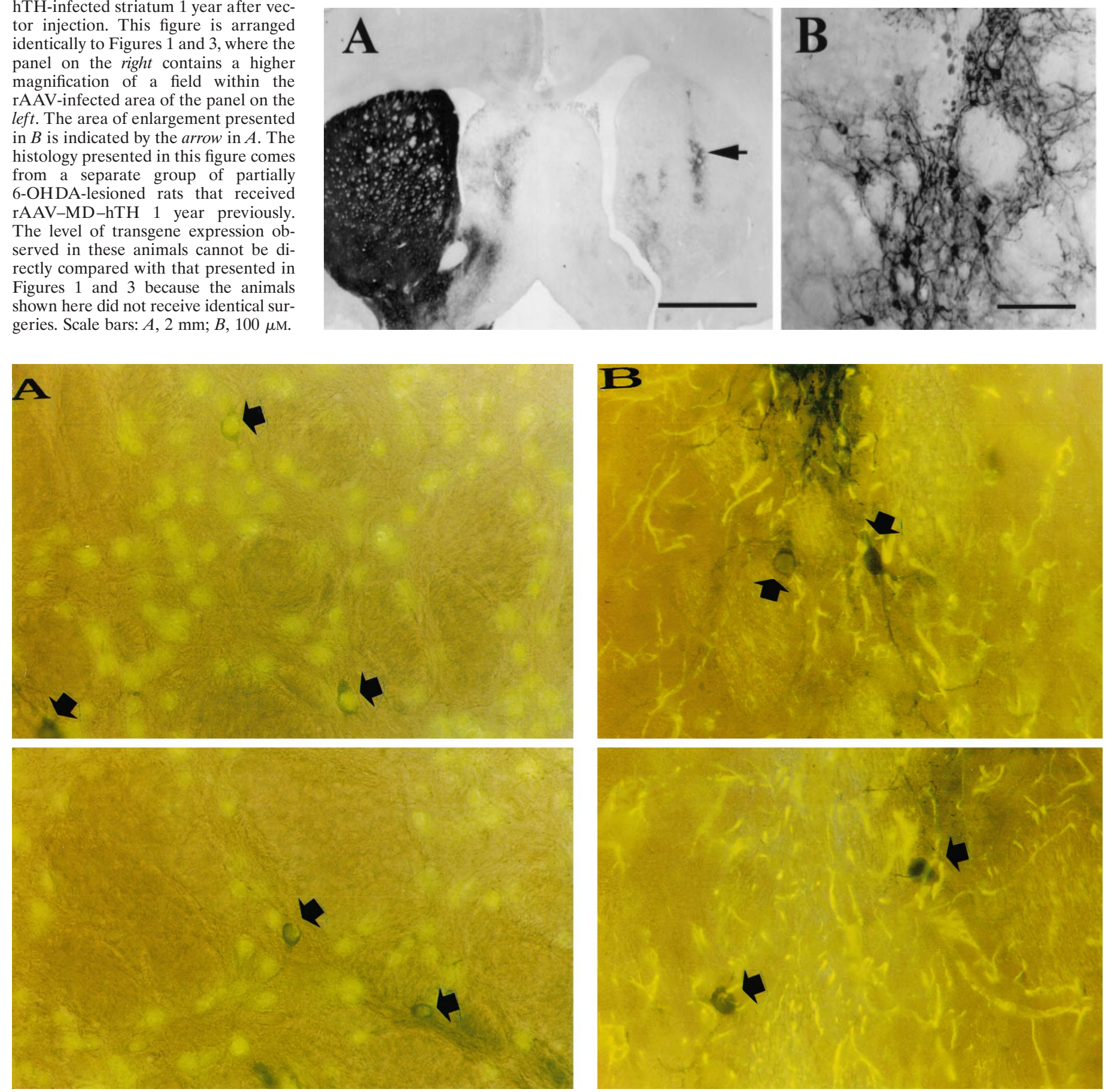

Figure 6. Neuronal specificity of rAAV-mediated hTH expression. $A$ contains a montage of two adjacent fields of NeuN-TH double-staining taken from an animal that received rAAV-MD-hTH 3 weeks before processing. The faint yellow staining is the ELF-labeled NeuN staining of neurons, and the darker grayish green staining (arrows) corresponds to $\mathrm{TH}^{+}$cells. In these fields, all of the $\mathrm{TH}^{+}$cells are double-stained with the NeuN marker. $B$ presents a representative section of a montage of two adjacent fields of a section double-stained for GFAP-TH. The GFAP staining is the yellow fiber staining, and the TH-stained cells (arrows) are the darker grayish green. None of the $\mathrm{TH}^{+}$cells are double-stained in this example.

groups, as reflected by a lack of a significant main effect of time course $\left(F_{(13,273)}=1.4 ; p>0.6\right)$ and a nonsignificant group $\times$ time course interaction $\left(F_{(39,273)}=0.7 ; p>0.9\right)$.

Figure 10 contains a representative example of the immunoblot analysis (Fig. 10, bottom) and L-DOPA tissue levels (Fig. 10, top) obtained from tissue punches taken $1.5 \mathrm{hr}$ after administration of NSD-1015 immediately after the cessation of the second micro- dialysis experiment. These data confirm the microdialysis data, i.e., all animals that received $\mathrm{rAAV}$ infections that encoded hTH (rAAV-MD-hTH and the 1:1 rAAV-MD-hTH + rAAV-MDhGTPCHI groups) displayed a positive protein band at the expected size for hTH, and these same groups yielded tissue levels of L-DOPA with the mixed vector-transduced group displaying the greatest L-DOPA levels. 
Table 2. Neuronal specificity of rAAV-MD-TH Expression

\begin{tabular}{|c|c|c|c|c|c|c|}
\hline \multirow[b]{2}{*}{ rAAV vector } & \multicolumn{3}{|c|}{ Neuronal specificity } & \multicolumn{3}{|c|}{ Astrocytic specificity } \\
\hline & $n$ & $\begin{array}{l}\mathrm{TH}^{+} \text {cells } \\
\text { sampled }\end{array}$ & $\begin{array}{l}\mathrm{NeuN}^{+} / \mathrm{TH}^{+} \\
\text {doubled stained }(\%)\end{array}$ & $n$ & $\begin{array}{l}\mathrm{TH}^{+} \text {cells } \\
\text { sampled }\end{array}$ & $\begin{array}{l}\mathrm{GFAP}^{+} / \mathrm{TH}^{+} \\
\text {doubled stained }(\%)\end{array}$ \\
\hline MD-TH & 3 & 414 & 92.5 & 4 & 786 & 1.3 \\
\hline MD-TH + MD-GTPCHI & 3 & 1187 & 96.2 & 3 & 807 & 1.2 \\
\hline
\end{tabular}

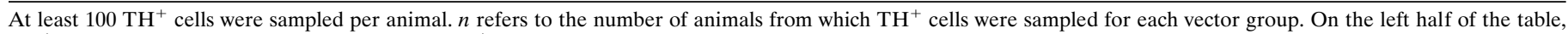

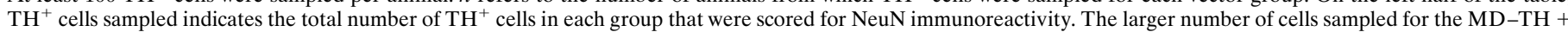

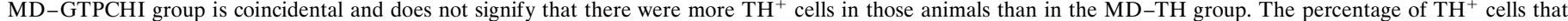

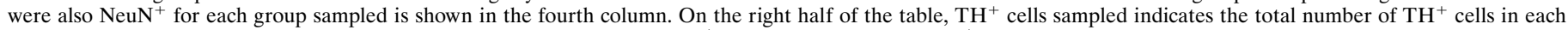
group that were scored for GFAP immunoreactivity. The percentage of $\mathrm{TH}^{+}$cells that were also $\mathrm{GFAP}^{+}$for each group sampled is shown in the last column.

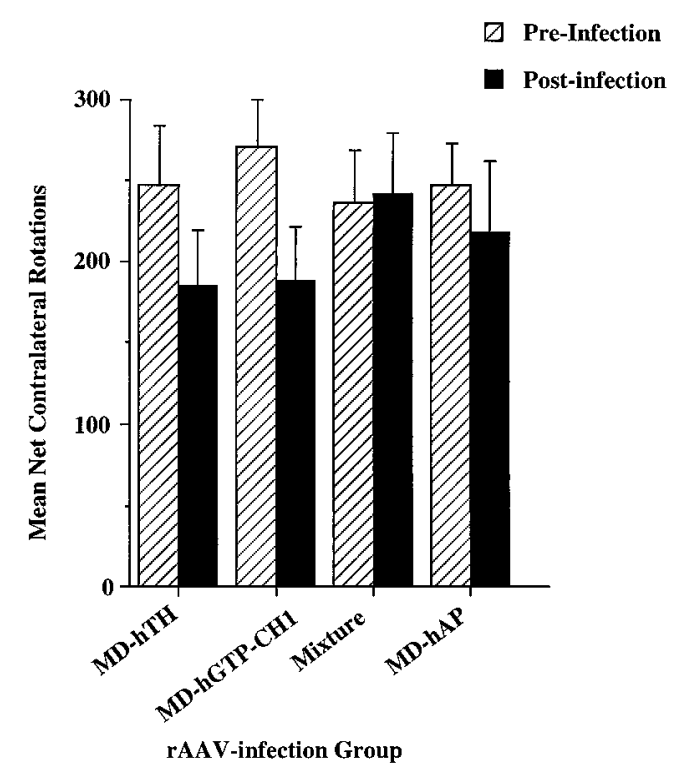

Figure 7. Effect of rAAV injections on apomorphine-induced rotation behavior. The groups are identified along the ordinate by which rAAV construct they received. The hatched bars represent the data obtained before intrastriatal vector injections ( + SEM), and the solid bars represent the level of apomorphine-induced contralateral rotations 3 weeks after intrastriatal vector infections. There were no significant differences between the groups before or after rAAV injection (for statistics see Results). Each bar represents the mean of 12 observations.

A separate group of 6-OHDA animals injected with rAAVMD-hAP prepared simultaneously with the animals used in the microdialysis study were examined for hAP immunohistochemistry and displayed positive staining in the striatum, indicating that this group was an appropriate control for transduction.

\section{DISCUSSION}

The present data indicate that $\mathrm{AAAV}$-mediated striatal transgene expression is demonstrable for at least 1 year under the control of a cytomegalovirus (CMV) promoter (MD). Striatal transgene expression after direct injection of rAAV has recently been reported for up to 4 or 7 months for a vector that coded human TH (Kaplitt et al., 1994; During and Leone, 1996). These investigators also reported that gene expression appeared to decline over this time period. The data presented here agree well with those earlier reports.

The present experiment also quantified the relative abundance of neurons expressing rAAV-delivered transgenes versus astrocytes. The results indicate that the overwhelming majority of striatal cells expressing the hTH transgene are neurons $(>90 \%$
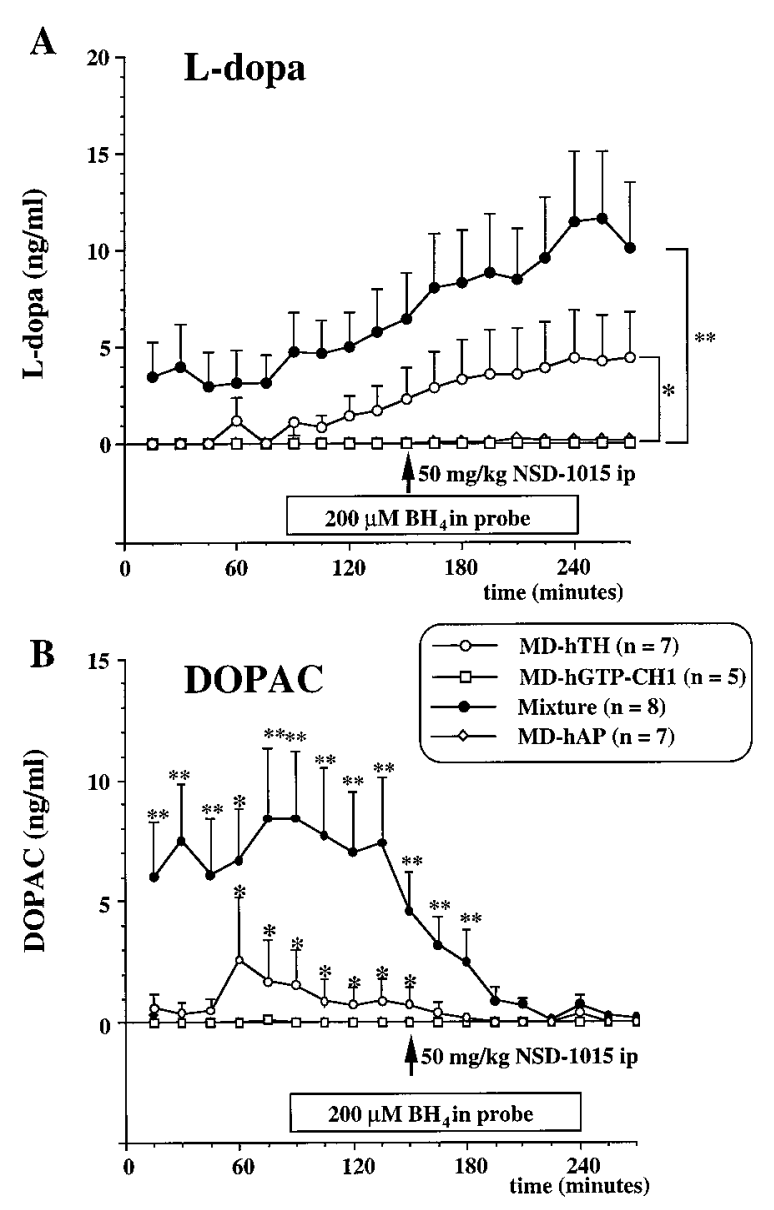

Figure 8. L-DOPA production and DOPAC levels 3 weeks after rAAV injections in the presence and absence of exogenous $\mathrm{BH}_{4}$ as measured by intrastriatal microdialysis. The symbols representing each rAAV-injected group along with their corresponding " $\mathrm{n}$ " number are presented in the figure legends $A$ and $B$. The rectangle under the graph in $A$ and $B$ indicates the duration of the infusion of $200 \mu \mathrm{M} \mathrm{BH}_{4}$ in the probe. $A$ presents the mean L-DOPA levels (+SEM) measured from the 15 min microdialysates sampled from each rAAV group. The data are expressed as nanograms per milligram, as indicated on the abscissa (for comparison: $1 \mathrm{ng} / \mathrm{ml}=5.1$ $\mu \mathrm{M})$. The closed bracket (]) followed by a single asterisk indicates that the entire curve is significantly different from the two control groups, rAAV$\mathrm{MD}-\mathrm{hAP}$ and rAAV-MD-hGTPCHI. The closed bracket (]) followed by the double asterisk indicates that the entire curve is significantly different from all other groups. $B$ contains the mean levels of the DA metabolite DOPAC $(+$ SEM $)$, measured from the same dialysate samples as reported in $A$. Double asterisks indicate statistical significance from all other groups, whereas single asterisks indicate significant differences from the two control groups, rAAV-MD-hAP and rAAV-MD-hGTPCHI. 


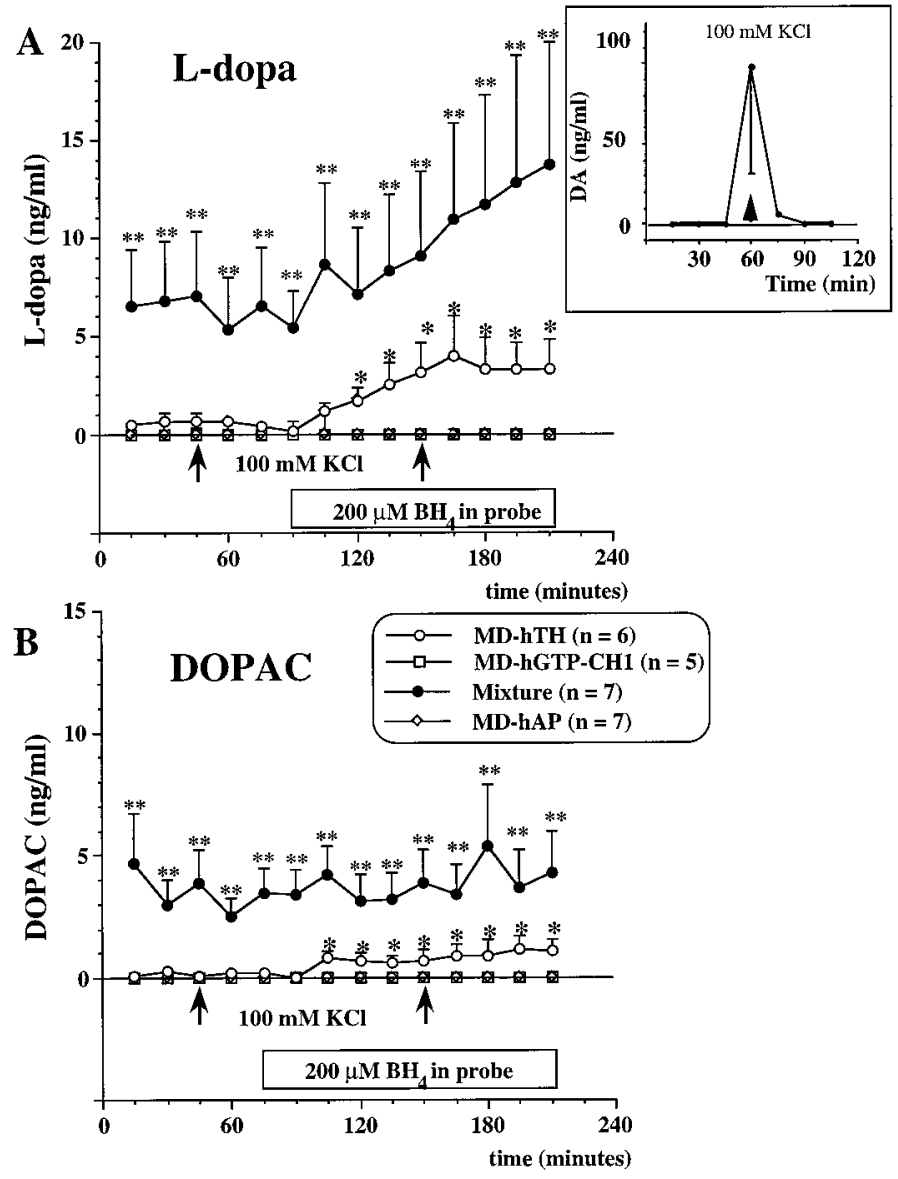

Figure 9. L-DOPA production and DOPAC levels 3 weeks after rAAV injections in the presence and absence of exogenous $\mathrm{BH}_{4}$ as measured by intrastriatal microdialysis: the effect of depolarization by $\mathrm{KCl}$ infusion. The symbols representing each rAAV-injected group along with their corresponding "n" number are presented in the figure legend for $A$ and $B$. The rectangle under the graph in $A$ and $B$ indicates the duration of the infusion of $200 \mu \mathrm{M} \mathrm{BH}$ in the probe. The arrows indicate the $15 \mathrm{~min}$ sample in which $100 \mathrm{~mm} \mathrm{KCl}$ was added to the dialysate in both $A$ and $B$. This experiment used the same animals as those used in Figure 8 and occurred $24 \mathrm{hr}$ after that experiment. $A$ presents the mean L-DOPA levels (+SEM) measured from the 15 min microdialysates sampled from each rAAV group. Before addition of $\mathrm{BH}_{4}$, only the group that received the intrastriatal injection of the 1:1 rAAV-MD-hTH and rAAV-MDhGTPCHI mixture displayed significant levels of L-DOPA. However, in contrast to the data presented in Figure 8, two animals that received intrastriatal rAAV-MD-hTH did display consistently low levels of L-DOPA before $\mathrm{BH}_{4}$ infusion $(1-2 \mathrm{ng} / \mathrm{ml})$. Double asterisks indicate statistical significance from all other groups, whereas single asterisks indicate significant differences from the two control groups, rAAV-MDhAP and rAAV-MD-hGTPCHI.

vs $<1 \%$ ). The neuronal specificity of rAAV-mediated striatal transgene expression has been suggested previously on the basis of morphological examination of the expressing cells, but not quantified (Kaplitt and During, 1996), but larger proportions of rAAV-mediated transgene expression in astrocytes have been reported using rAAV-CMV-lacZ (Blömer et al., 1997). Similar neuronal specificity in striatum for transgene expression has recently been reported for recombinant replication defective lentivirus (Naldini et al., 1996). The mechanism of this specificity is currently unknown but is apparently independent of the transgene (hGTPCHI expression appears to be neuronal by morphological criteria similar to that seen for hTH). These data indicate
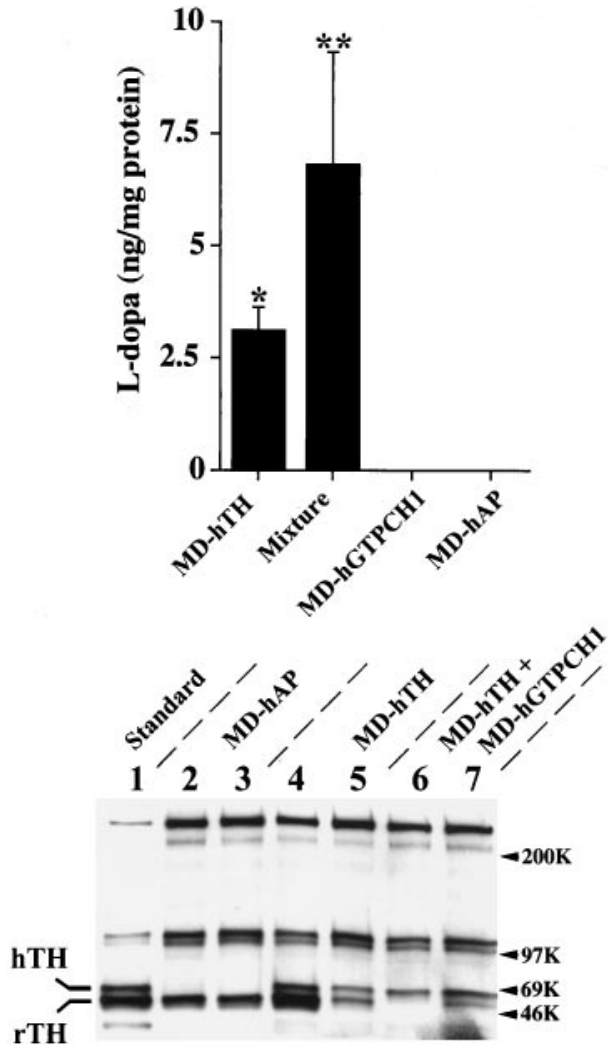

Figure 10. L-DOPA levels and immunoblots showing anti-TH immunoreactivity measured from punches from rAAV-infected striatum. Top, L-DOPA levels. The animals used in the dialysis experiments (Figs. 9, 10) were injected with NSD-1015 (50 mg/kg, i.p.) immediately after the cessation of sample collection. Ninety minutes to $2 \mathrm{hr}$ later, striatal punches were taken from the area of the tract left by the removal of the microdialysis probe. The single asterisk indicates that the L-DOPA levels measured from punches from the rAAV-MD-hTH group $(n=6)$ were significantly greater than those measured in the rAAV-MD-hGTPCHI group $(n=4)$ or the rAAV-MD-hAP group $\left(n=7 ; F_{(1,20)}=5.2 ; p=\right.$ 0.03 ). The double asterisks indicate that the group receiving the 1:1 rAAV-MD-hTH and rAAV-MD-hGTPCHI mixture $(n=6)$ displayed significantly higher striatal L-DOPA content than the other groups $\left(F_{(1,20)}\right.$ $=20.3 ; p<0.001)$. Bottom, Immunoblots of homogenates of punches from rAAV-infected striatum showing anti-TH immunoreactivity. Lane 1 (Standard) shows $0.1 \mu \mathrm{g}$ protein from unlesioned rat striatum mixed with protein from 1000 rat fibroblasts transduced with the retroviral vector MFG-hTH2 (Leff et al., 1998). Proteins expressed from the endogenous rat gene $(\mathrm{rTH})$ and the transduced human cDNA (hTH) are discriminated by size because of a four amino-acid insertion found in the hTH2 variant not found in $\mathrm{rTH}$. Protein $(5 \mu \mathrm{g})$ from homogenates of punches from lesioned striatum infected with the AAV vectors shown was run in lanes 2 through 7. Relative band intensities for rTH show the residual rTH after 6-OHDA lesions. Relatively abundant hTH bands are present in lanes 4-7, which include infections by the AAV-MD-hTH vector. The nonspecific high molecular weight bands are caused by cross-reactivity with the secondary antibody because these bands are also present when the primary anti-TH antibody is not used. Molecular weight markers are indicated on the right side of the blot.

that neuronal specificity or bias of expression is attributable to some property of the rAAV infection or the expression process itself or both.

The microdialysis data presented here represent the first study using rAAV to report measurement of striatal L-DOPA production arising from transgenic expression of genes in the normal biochemical pathway for DA synthesis. Microdialysis data for L-DOPA and DOPAC production are shown in Figures 8 and 9. 
The DA data are not shown because DA levels were not consistently above the detection limits of our assay $(1 \mathrm{ng} / \mathrm{ml})$. However, because DOPAC is a metabolite of DA, the presence of striatal DOPAC in the dialysates strongly suggests the presence of striatal DA. Moreover, the declines in DOPAC that are observed after NSD-1015 injection clearly demonstrate that in animals in which L-DOPA was synthesized, the L-DOPA was converted to DA by AADC. Presumably, in the absence of dopaminergic terminals in the 6-OHDA-lesioned striatum, the rapid turnover of DA by monoamine oxidase results in unmeasurable levels of extracellular DA.

The data presented here clearly demonstrate that some form of $\mathrm{BH}_{4}$ delivery is necessary to allow transgenic $\mathrm{TH}$ to synthesize L-DOPA in the 6-OHDA-lesioned striatum as reported. Coinfection with the primary synthetic enzyme for $\mathrm{BH}_{4}$, GTPCHI, or exogenous local application of $\mathrm{BH}_{4}$, along with hTH expression, was sufficient to allow measurement of striatal L-DOPA. This finding is consistent with microdialysis studies reported previously for rat dermal fibroblasts retrovirally transduced with both GTPCHI and TH (Bencsics et al., 1996; Leff et al., 1998) or addition of $\mathrm{BH}_{4}$ (Uchida et al., 1992). Because it is likely that not all striatal neurons were co-infected with GTPCHI and TH, the in vivo data presented here suggest that a trans-cellular effect of $\mathrm{BH}_{4}$ on $\mathrm{TH}$ activity may occur, i.e., $\mathrm{BH}_{4}$ or dihydrobiopterin may be capable of leaving one cell and acting as a co-factor in another cell possibly after recycling by dihydrobiopterin reductase. Indeed, we and others have previously collected in vitro data that also indicate that a trans-cellular effect of $\mathrm{BH}_{4}$ on $\mathrm{TH}$ activity could occur (Anastasiadis et al., 1994; Leff et al., 1998).

The possibility that $\mathrm{BH}_{4}$ affects $\mathrm{TH}$ activity via trans-cellular trafficking raises the question of whether there may be enough striatal $\mathrm{BH}_{4}$ remaining in PD patients to allow transgenic $\mathrm{TH}$ expression to be therapeutic via synthesis of local L-DOPA. In intact rat striatum, the levels of $\mathrm{BH}_{4}$ have been reported to be $\sim 1$ $\mu \mathrm{M}$ (Levine et al., 1979), and a unilateral 6-OHDA lesion that reduced $\mathrm{TH}$ activity by $93 \%$ reduced $\mathrm{BH}_{4}$ levels $73 \%$, indicating that the majority of striatal $\mathrm{BH}_{4}$ resides in nigrostriatal DA terminals (Levine et al., 1981). Thus, even if all of the $\mathrm{BH}_{4}$ remaining in a DA denervated striatum was available to cellular compartments outside of nigrostriatal terminals, $<1 \mu \mathrm{M}$ would be available to cells transduced with hTH. Because the $K_{\mathrm{m}}$ of $\mathrm{BH}_{4}$ for activation of phosphorylated $\mathrm{TH}$ is reported to be $10-30 \mu \mathrm{M}$ (Levine et al., 1981), the low levels of endogenous $\mathrm{BH}_{4}$ in the lesioned striatum would not be expected to yield much $\mathrm{TH}$ activity and therefore L-DOPA. Indeed, in the present study, the perfusion of $\mathrm{BH}_{4}$ through the microdialysis probes was necessary to detect any striatal L-DOPA in the rAAV-MD-hTH-injected group. The $\mathrm{BH}_{4}$ infusion probably leads to an estimated local concentration of $40 \mu \mathrm{M} \mathrm{BH} 4(200 \mu \mathrm{M} \times 20 \%$ recovery rate for probes), which resulted in a measurable but low level of L-DOPA production. Similar to the situation in the 6-OHDA lesion model, $\mathrm{BH}_{4}$ has been shown to be reduced in PD (Lovenberg et al., 1979; Nagatsu et al., 1981, 1984; LeWitt et al., 1984). Given that $\mathrm{BH}_{4}$ is present at low levels in intact striatal tissue and that L-DOPA synthesis by $\mathrm{TH}$ is so strongly dependent on $\mathrm{BH}_{4}$ cofactor, it appears that either GTPCHI must be co-expressed or exogenous $\mathrm{BH}_{4}$ must be supplied along with $\mathrm{TH}$ for production of L-DOPA to be achieved in any attempted L-DOPA gene therapy for PD.

In light of the data presented here, which indicate that the vast majority of the striatal cells expressing rAAV-delivered transgenes are neurons, the mode of egress of transgenically produced
L-DOPA becomes an important question. In the second microdialysis experiment (Fig. 6), a depolarizing stimulus was delivered via the microdialysis probe to determine whether striatal L-DOPA was released via an electrogenic-dependent mechanism. Addition of excess potassium had no effect on the measurement of L-DOPA or DOPAC regardless of the status of $\mathrm{BH}_{4}$. Therefore, the transgenically produced L-DOPA was released from the rAAVtransduced striatal neurons through a different mechanism than that used by vesicle-bound neurotransmitters. Because L-DOPA is an amino acid, the most probable mode of release of L-DOPA in this case is via constitutive neutral amino acid transport mechanisms. Consequently, the normal functioning of these neurons may not be disrupted by de novo synthesis of L-DOPA.

Although the present study demonstrates rAAV-mediated striatal L-DOPA synthesis in 6-OHDA-lesioned rats, no effects on behavior were found. Reductions in apomorphine-induced rotational behavior is currently used as an important indicator of the presence of increased dopaminergic tone in the unilateral 6-OHDA lesion model of PD in the rat. Expectations of changes in the apomorphine-induced rotational behavior paradigm stems from the proposed biological mechanism underlying reduction of apomorphine-induced rotations, i.e., reduction of striatal DA receptor hypersensitivity (Freed et al., 1983; Cenci et al., 1992). Furthermore, the concordance between reductions in apomorphine induced rotations in the fetal nigral transplantation literature and the clinical results achieved in PD patients with similar transplants suggests that this test may be clinically predictive (Lindvall and Odin, 1994; Lindvall, 1995). Although in this experiment $\mathrm{BH}_{4}$-independent L-DOPA levels were reliably measured in all animals infected with the 1:1 rAAV-MD-hTH and rAAV-MD-hGTPCHI mixture 3-4 weeks after injection, there was no significant reduction of apomorphine-induced rotations in any group. There are two potential reasons for the lack of effect on rotational behavior observed in this experiment. Either the levels of striatal L-DOPA released from infected cells were not sufficient to reduce the behavioral supersensitivity in these animals or chronic continuous L-DOPA does not affect apomorphine-induced rotational behavior. The hypothesis that insufficient L-DOPA was produced to affect the apomorphineinduced rotational behavior cannot be rejected on the basis of the data presented here.

In support of the latter possibility, i.e., that chronic L-DOPA does not reduce apomorphine-induced rotational behavior in the unilateral 6-OHDA lesion model, one study in which L-DOPA was delivered chronically for 4 weeks using high doses of systemic L-DOPA reported increased or unchanged apomorphine-induced rotations at one L-DOPA dose (Gnanalingham and Robertson, 1993). Two additional studies have looked at the effects on apomorphine-induced rotations after either continuous L-DOPA delivered via osmotic minipumps (19 d) or by daily injection (10 d) (Engber et al., 1989; Asin et al., 1995). In both studies, apomorphine-induced rotations were increased after chronic L-DOPA treatment, but these studies also pointed out a differential effect on D-1 and D-2 agonist-induced rotational behavior. Nevertheless, a significant decrease of apomorphine-induced rotational behavior has never been reported after any chronic regimen of L-DOPA administration. It has been observed that chronic L-DOPA has previously been shown to improve various striatal neuropeptide expression levels after unilateral 6-OHDAinduced DA denervation (Engber et al., 1991). Therefore, in future studies using this gene transfer paradigm to produce striatal L-DOPA after DA denervation, measurement of striatal 
neuropeptide levels might provide a dissociation between apomorphine-induced rotational behavior and functional effects of transgenic L-DOPA on these striatal peptides that would help resolve this issue.

Several aspects of our findings regarding L-DOPA production after $\mathrm{rAAV}-\mathrm{TH}$ transduction are inconsistent with those of another study involving injection of HSV-TH into the 6-OHDAlesioned rat striatum (During et al., 1994). First, these authors reported measurable L-DOPA release after HSV-TH infections in the absence of exogenously supplied $\mathrm{BH}_{4}$. In the HSV-TH study the L-DOPA levels in dialysis samples after NSD-1015 were approximately twofold higher than those obtained in the present study after striatal co-injection with rAAV hTH and hGTPCHI, although the infections were much less efficient in the HSV study (5-200 TH-immunopositive cells per striatum) as compared with 250-9500 (Abercrombie corrected counts; the raw counts were 2-10 times greater) observed after infection with rAAV-MDTH. Both studies report using animals with complete 6-OHDA lesions as assayed by apomorphine-induced rotations. However, in the HSV study measurable levels of L-DOPA (>50 nM) were obtained in 6-OHDA-lesioned control animals, which was not the case in the present study even after NSD-1015 treatment and application of exogenous $\mathrm{BH}_{4}$. The presence of measurable L-DOPA in control lesioned striatum in the HSV-TH report raises concerns about the actual extent of the 6-OHDA lesion in those animals, which further complicates the interpretation of the source of L-DOPA from the HSV-TH-infected striata (During et al., 1994).

The second major difference between our findings and that of the HSV-TH study regards the observed depolarization-induced DA release in HSV-TH-infected animals (During et al., 1994). The presence of depolarization-induced DA release in the control animals in the HSV-TH study suggests that residual DA fibers were present in the vicinity of the microdialysis probe, which renders interpretation of depolarization-induced DA release in the HSV-TH experimental group difficult (During et al., 1994). Nevertheless, if HSV-mediated TH gene expression was responsible for the heightened depolarization-dependent DA release in infected animals, then it would suggest that the DA synthesized as a result of transgenic L-DOPA production was vesicularized and released in a physiological manner. However, striatal serotonergic neurons, the one compartment containing residual AADC after a 6-OHDA lesion that also has the cellular machinery to vesicularize DA (Melamed et al., 1979, 1980a,b, 1981; Hefti et al., 1980, 1981; Mura et al., 1995), do not appear to be numerous enough in the area of the probe to support the reported DA release.

In addition to the disparate findings regarding the L-DOPA production mentioned above, in contrast to the findings reported here, two groups have reported significant reductions of apomorphine-induced rotational behavior after intrastriatal injection of either Ad (Horellou et al., 1994) or HSV (During et al., 1994) vectors encoding TH in 6-OHDA-lesioned rats. As discussed above, it is questionable whether striatal L-DOPA delivery would be expected to cause a reduction of apomorphine-induced rotational behavior. Furthermore, in the case of intrastriatal viral injections, toxic reactions to the viral infection or expression of viral proteins can occur (Isacson, 1995; Neve and Geller, 1996), and because striatal damage (which removes DA receptors) has been shown to reduce apomorphine-induced rotations in rough correlation to the amount of damage (Barker and Dunnett, 1994), this behavioral paradigm may be an unreliable predictor in a gene therapy setting. Therefore, even when using appropriate control groups in a gene therapy paradigm such as the use of identical vectors encoding an irrelevant transgene, reductions of apomorphine-induced rotational behavior may indicate greater toxicity of the TH-expressing group rather than successful delivery of L-DOPA (Isacson, 1995). This hypothesis is consistent with the observation of minimal histopathology and lack of rotational decline in animals with measurable rAAV-mediated striatal L-DOPA production in the present experiment. Indeed, the two other groups reporting positive behavioral effects of striatal expression of TH alone used Ad (Horellou et al., 1994) and HSV vectors (During et al., 1994), two vector systems that have been reported to cause significant neurotoxicity (Isacson, 1995; Neve and Geller, 1996).

The Ad vector study did not measure striatal L-DOPA. Consequently, it cannot be directly evaluated whether L-DOPA or striatal toxicity induced the reported changes in apomorphineinduced rotational behavior (Horellou et al., 1994). In addition, the magnitude of reduction of rotational behavior was highly variable, with the extent of rotational reduction in the experimental Ad-infected group and the $L a c Z$ control greatly overlapping (Horellou et al., 1994). Inspection of the data reveals that although $66 \%$ of the Ad-TH-injected rats reduced their apomorphine-induced rotational response 1 week after Ad infection, $47 \%$ of the Ad-lacZ animals reduced their rotational behavior as well (Horellou et al., 1994).

A much greater reduction of apomorphine-induced rotational behavior was reported after intrastriatal HSV-TH compared with either striatal PBS or HSV-LacZ injections (During et al., 1994). As discussed above, the HSV-TH study also reported striatal L-DOPA production. However, the rotational behavior portion of the HSV report has been called into question (Isacson, 1995). A technical note written in response to the HSV-TH study indicated that, using "... the same viral stocks, titers, and volumes. .." as used for intrastriatal injections in the original HSV report, pronounced striatal damage was observed that probably accounted for the reductions in HSV-induced rotational reductions observed in the second laboratory (Isacson, 1995). Therefore, disparate behavioral findings from another laboratory combined with the concerns about the extent of the 6-OHDA noted above raise doubts about whether the HSV data are actually in disagreement with the data presented here.

As has been concluded previously (Kaplitt and During, 1996; McCown et al., 1996), given the longevity of rAAV-mediated striatal transgene expression, the neuronal specificity of striatal transgene expression, and the low liability of rAAV to revert to wild type and support a productive and pathogenic infection, rAAV is an extremely attractive vehicle for intracerebral gene transfer. Therefore, rAAV vectors may ultimately provide the opportunity to develop treatments for neurological disorders that require continuous delivery of gene products in a site-specific manner. Characterization of any adverse reactions to intracerebral infections with rAAV is an important issue that has not been adequately examined to date. It has been asserted previously that intrastriatal injections of rAAV "appears safe" (Kaplitt et al., 1994; During and Leone, 1996; Kaplitt and During, 1996), but more detailed histopathology is necessary to actually make this conclusion. Although the present study was not designed to examine toxicity, Nissl-stained sections were examined (data not shown), and no obvious local histopathology was identified. Moreover, as mentioned above, the stability of apomorphine-induced rotational behavior before and after vector injection argues in 
favor of low toxicity. Before human studies with rAAV can be initiated, studies to define the relationship among injection parameters, transgene expression, and toxicity must be determined. Nevertheless, the data collected here and reported elsewhere (Kaplitt et al., 1994; Kaplitt and During, 1996) indicate that human gene therapy using $\mathrm{rAAV}$ in the CNS remains a promising possibility.

\section{REFERENCES}

Abercrombie M (1946) Estimation of nuclear population from microtome sections. Anat Record 94:239-247.

Anastasiadis PZ, Kuhn DM, Levine RA (1994) Tetrahydrobiopterin uptake into rat brain synaptosomes, cultured PC12 cells, and rat striatum. Brain Res 665:77-84.

Asin KE, Bednarz L, Nikkel A, Perner R (1995) Rotation and striatal c-fos expression after repeated, daily treatment with selective dopamine receptor agonists and levodopa. J Pharmacol Exp Ther 273:14831490.

Barker R, Dunnett SB (1994) Ibotenic acid lesions of the striatum reduce drug-induced rotation in the 6-hydroxydopamine-lesioned rat. Exp Brain Res 101:365-374.

Bencsics C, Wachtel SR, Milstien S, Hatakeyama K, Becker JB, Kang UJ (1996) Double transduction with GTP cyclohydrolase I and tyrosine hydroxylase is necessary for spontaneous synthesis of L-DOPA by primary fibroblasts. J Neurosci 16:4449-4456.

Björklund A (1991) Neural transplantation: an experimental tool with clinical possibilities. Trends Neurosci 14:319-322.

Blömer U, Naldini L, Kafri T, Trono D, Verma IM, Gage FH (1997) Highly efficient and sustained gene transfer in adult neurons and lentivirus vector. J Virol 71:6641-6649.

Brundin P, Barbin G, Strecker RE, Isacson O, Prochiantz A, Björklund A (1988) Survival and function of dissociated rat dopamine neurones grafted at different developmental stages or after being cultured in vitro. Dev Brain Res 39:233-243.

Cenci MA, Kalén P, Mandel RJ, Wictorin K, Björklund A (1992) Dopaminergic transplants normalize amphetamine- and apomorphineinduced Fos expression in the 6-hydroxydopamine-lesioned striatum. Neuroscience 46:943-958.

Chase TN, Baronti F, Fabbrini G, Heuser IJ, Juncos JL, Mouradian MM (1989) Rationale for continuous dopaminomimetic therapy of Parkinson's disease. Neurology 39:7-10.

Chase TN, Mouradian MM, Engber TM (1993) Motor response complications and the function of striatal efferent systems. Neurology 43:23-27.

Cullen BR (1986) Trans-activation of human immunodeficiency virus occurs via a bimodal mechanism. Cell 46:973-982.

During MJ, Leone P (1996) Adeno-associated virus vectors for gene therapy of neurodegenerative disorders. Clin Neurosci 3:292-300.

During MJ, Naegele JR, O'Malley KL, Geller AI (1994) Long-term behavioral recovery in parkinsonian rats by an HSV vector expressing tyrosine hydroxylase. Science 266:1399-1403.

Engber TM, Susel Z, Juncos JL, Chase TN (1989) Continuous and intermittent levodopa differentially affect rotation induced by D-1 and D-2 dopamine agonists. Eur J Pharmacol 168:291-298.

Engber TM, Susel Z, Kuo S, Gerfen CR, Chase TN (1991) Levodopa replacement therapy alters enzyme activities in striatum and neuropeptide content in striatal output regions of 6-hydroxydopamine lesioned rats. Brain Res 552:113-118.

Ferrari FK, Samulski T, Shenk T, Samulski RJ (1996) Second-strand synthesis is a rate-limiting step for efficient transduction by recombinant adeno-associated virus vectors. J Virol 70:3227-3234.

Freed CR, Breeze RE, Rosenberg NL, Schneck SA, Kriek E, Qi J-X, Lome T, Zhang Y-B, Snyder JA, Wells TH, Olson RL, Thompson L, Mazziotta JC, Huang SC, Grafton ST, Brooks D, Sawle G, Schroter G, Ansari AA (1992) Survival of implanted fetal dopamine cells and neurologic improvement 12 to 46 months after transplantation for Parkinson's disease. N Engl J Med 327:1549-1555.

Freed WJ, Ko GN, Niehoff D, Kuhar M, Hoffer BJ, Olson L, CannonSpoor E, Morihisa JM, Wyatt RJ (1983) Normalization of spiroperidol binding in the denervated rat striatum by homologous grafts of substantia nigra. Science 222:937-939.

Gage FH, Wolff JA, Rosenberg MB, Xu L, Yee J-K, Shults C, Friedmann $\mathrm{T}$ (1987) Grafting genetically modified cells to the brain: possibilities for the future. Neuroscience 23:795-807.
Gnanalingham KK, Robertson RG (1993) Chronic continuous and intermittent L 34 dihydroxyphenylalanine treatments differentially affect basal ganglia function in 6 hydroxydopamine lesioned rats an autoradiographic study using ${ }^{3} \mathrm{H}$ flunitrazepam. Neuroscience 57:673-681.

Gundersen HJG, Bagger P, Bendtsen TF, Evans SM, Korbo L, Marcussen N, Moller A, Nielsen K, Nyengaard JR, Pakkenberg B, Sorensen FB, Vesterby A, West MJ (1988a) The new stereological tools: dissector, fractionator, nucleator and point sampled intercepts and their use in pathological research and diagnosis. Acta Pathol Microbiol Immunol Scand 96:857-881.

Gundersen HJG, Bendtsen TF, Korbo L, Marcussen N, Möller A, Nielsen K, Nyengaard JR, Pakkenberg B, Sörensen FB, Vesterby A, West MJ (1988b) Some new, simple and efficient stereological methods and their use in pathological research and diagnosis. Acta Pathol Microbiol Immunol Scand 96:379-394.

Guo ZS, Wang L-H, Eisensmith RC, Woo SLC (1996) Evaluation of promoter strength for hepatic gene expression in vivo following adenovirus-mediated gene transfer. Gene Ther 3:802-810.

Gutlich M, Jaeger E, Rucknagel KP, Werner T, Rodl W, Ziegler I, Bacher A (1994) Human GTP cyclohydrolase I: only one out of three cDNA isoforms gives rise to the active enzyme. Biochem J 302:215-221.

Hefti F, Melamed E, Wurtman RJ (1980) The decarboxylation of DOPA in the parkinsonian brain: in vivo studies on an animal model. J Neural Transm Suppl 16:95-101.

Hefti F, Melamed E, Wurtman RJ (1981) The site of dopamine formation in rat striatum after L-DOPA administration. J Pharmacol Exp Ther 217:189-197.

Hofland HEJ, Nagy D, Liu J-J, Spratt K, Lee Y-L, Danos O, Sullivan SM (1997) In vivo gene transfer by intravenous administration of stable cationic lipid/DNA complex. Pharmaceut Res 14:742-749.

Horellou P, Vigne E, Castel MN, Barneoud P, Colin P, Perricaudet M, Delaere P, Mallet J (1994) Direct intracerebral gene transfer of an adenoviral vector expressing tyrosine hydroxylase in a rat model of Parkinson's disease. NeuroReport 6:49-53.

Hurn BA, Chantler SM (1980) Production of reagent antibodies. Methods Enzymol 70:104-142.

Isacson O (1995) Behavioral effects and gene delivery in a rat model of Parkinson's disease. Science 269:856-857.

Kalén P, Strecker RE, Rosengren E, Björklund A (1988) Endogenous release of neuronal serotonin and 5-hydroxyindoleacetic acid in the caudate-putamen of the rat as revealed by intracerebral dialysis coupled to high-performance liquid chromatography with fluorimetric detection. J Neurochem 51:1422-1435.

Kaplitt MG, During MJ (1996) Transfer and expression of potentially therapeutic genes into mammalian central nervous system in vivo using adeno-associated viral vectors. In: Viral vectors (Kaplitt MG, Loewy AD, eds), pp 193-210. New York: Academic.

Kaplitt MG, Leone P, Samulski RJ, Xiao X, Pfaff DW, O'Malley KL, During MJ (1994) Long term gene expression and phenotypic correction using adeno-associated virus vectors in the mammalian brain. Nat Genet 8:148-153.

Kirk RE (1968) Experimental design: procedures for the behavioral sciences. Belmont, CA: Brooks/Cole.

Kordower JH, Freeman TB, Snow BJ, Vingerhoets FJG, Mufson EJ, Sanberg PR, Hauser RA, Smith DA, Nauert GM, Perl DP, Olanow CW (1995) Neuropathological evidence of graft survival and striatal reinnervation after transplantation of fetal mesencephalic tissue in a patient with Parkinson's disease. N Engl J Med 332:1118-1124.

Larison KD, BreMiller R, Wells KS, Clements I, Haugland RP (1995) Use of a new fluorogenic phosphatase substrate in immunohistochemical applications. J Histochem Cytochem 43:77-83.

Leff SE, Spratt SK, Rendahl KG, Mandel RJ (1998) In vivo L-dopa production by genetically modified primary rat fibroblast or 9L gliosarcoma cell grafts requires co-expression of GTP-cyclohydrolase I with tyrosine hydroxylase. Exp Neurol, in press.

Levine RA, Kuhn DM, Lovenberg W (1979) The regional distribution of hydroxylase cofactor in rat brain. J Neurochem 32:1575-1578.

Levine RA, Miller LP, Lovenberg W (1981) Tetrahydrobiopterin in striatum: localization in dopamine nerve terminals and role in catecholamine synthesis. Science 214:919-921.

LeWitt PA, Miller LP, Newman RP, Burns RS, Insel T, Levine RA, Lovenberg W, Calne DB (1984) Tyrosine hydroxylase cofactor (tetrahydrobiopterin) in parkinsonism. Adv Neurol 40:459-462.

Lindvall O (1995) Neural transplantation. Cell Transplant 4:393-400. 
Lindvall O, Odin P (1994) Clinical application of cell transplantation and neurotrophic factors in CNS disorders. Curr Opin Neurobiol 4:752-757.

Lovenberg W, Levine RA, Robinson DS, Ebert M, Williams AC, Calne DB (1979) Hydroxylase cofactor activity in cerebrospinal fluid of normal subjects and patients with Parkinson's disease. Science 204:624-626.

Mandel RJ, Leanza G, Nilsson OG, Rosengren E (1994) Amphetamine induces excess release of striatal acetylcholine in vivo that is independent of nigrostriatal dopamine. Brain Res 653:57-65.

Mandel RJ, Spratt SK, Snyder RO, Leff SE (1997) Midbrain injection of recombinant adeno-associated virus encoding rat glial cell line-derived neurotrophic factor protects nigral neurons in a progressive 6-hydroxydopamine-induced degeneration model of Parkinson's disease in rats. Proc Natl Acad Sci USA 94:14083-14088.

McCown TJ, Xiao X, Li J, Breese GR, Samulski RJ (1996) Differential and persistent expression patterns of CNS gene transfer by an adenoassociated virus (AAV) vector. Brain Res 713:99-107.

Melamed E, Hefti F, Wurtman RJ (1979) Nonaminergic striatal neurons convert exogenous L-DOPA to dopamine in Parkinsonism. Ann Neurol 8:558-563.

Melamed E, Hefti F, Wurtman RJ (1980a) Diminished decarboxylation of L-DOPA in rat striatum after intrastriatal injections of kainic acid. Neuropharmacology 19:409-411.

Melamed E, Hefti F, Wurtman RJ (1980b) Decarboxylation of exogenous L-DOPA in rat striatum after lesions of the dopaminergic nigrostriatal neurons: the role of striatal capillaries. Brain Res 198:244-248.

Melamed E, Hefti F, Pettibone DJ, Liebman J, Wurtman RJ (1981) Aromatic L-amino acid decarboxylase in rat corpus striatum: implications for action of L-dopa in parkinsonism. Neurology 31:651-655.

Mullen RJ, Buck CR, Smith AM (1992) NeuN, a neuronal specific nuclear protein in vertebrates. Development 116:201-211.

Mura A, Jackson D, Manley MS, Young SJ, Groves PM (1995) Aromatic L-amino acid decarboxylase immunoreactive cells in the rat striatum: a possible site for the conversion of exogenous L-DOPA to dopamine. Brain Res 704:51-60.

Muzyczka N (1992) Use of adeno associated virus as a general transduction vector for mammalian cells. Curr Top Microbiol Immunol 158:97-129.

Nagatsu T, Yamaguchi T, Kato T, Sugimoto T, Matsuura S, Akino M, Nagatsu I, Iizuka R, Narabayashi H (1981) Biopterin in human brain and urine from controls and Parkinsonian patients: application of new radioimmunoassay. Clin Chim Acta 109:305-311.

Nagatsu T, Yamaguchi T, Rahman MK, Trocewicz J, Oka K, Hirata Y, Nagatsu I, Narabayashi H, Kondo T, Iizuka R (1984) Catecholaminerelated enzymes and the biopterin cofactor in Parkinson's disease and related extrapyramidal diseases. Adv Neurol 40:467-473.

Naldini L, Blömer U, Gallay P, Ory D, Mulligan R, Gage FH, Verma IM, Trono D (1996) In vivo gene delivery and stable transduction of nondividing cells by a lentiviral vector. Science 272:263-267.

Neve RL, Geller AI (1996) A defective herpes simplex virus vector system for gene delivery into the brain: comparison with alternative gene delivery systems and usefulness for gene therapy. Clin Neurosci 3:262-267.
Obeso JA, Grandas F, Herrero MT, Horowski R (1994) The role of pulsatile versus continuous dopamine receptor stimulation for functional recovery in Parkinson's disease. Eur J Neurosci 6:889-897.

Paxinos G, Watson C (1987) The rat brain in stereotaxic coordinates. San Diego: Academic.

Samulski RJ, Chang LS, Shenk T (1989) Helper-free stocks of recombinant adeno-associated viruses: normal integration does not require viral gene expression. J Virol 63:3822-3828.

Schmidt RH, Björklund A, Stenevi U, Dunnett SB, Gage FH (1983) Intracerebral grafting of neuronal cell suspensions III. Activity of intrastriatal nigral suspension implants as assessed by measurements of dopamine synthesis and metabolism. Acta Physiol Scand 522:19-28.

Schuh LA, Bennett JP (1993) Suppression of dyskinesias in advanced Parkinson's disease. I. Continuous intravenous levodopa shifts dose response for production of dyskinesias but not for relief of parkinsonism in patients with advanced Parkinson's disease. Neurology 43:1545-1550.

Sigel MB, Sinha YN, VanderLaan WP (1983) Production of antibodies by inoculation into lymph nodes. Methods Enzymol 93:3-12.

Snyder RO, Miao CH, Patijn GA, Spratt SK, Danos O, Gown AM, Winther B, Meuse L, Cohen LK, Thompson AR, Kay MA (1997) Persistent and therapeutic concentrations of human factor IX in mice after hepatic gene transfer of recombinant AAV vectors. Nat Genet 16:270-276.

Spencer DD, Robbins RJ, Naftolin F, Marek KL, Vollmer T, Leranth C, Roth RH, Price LH, Gjedde A, Bunney BS, Sass KJ, Elsworth JD, Kier EL, Makuch R, Hoffer PB, Redmond Jr DE (1992) Unilateral transplantation of human fetal mesencephalic tissue into the caudate nucleus of patients with Parkinson's disease. N Engl J Med 327:1541-1548.

Sternberger LA, Hardy PH, Cuculis JJ, Meyer HG (1970) The unlabelled antibody-enzyme method of immunohistochemistry. Preparation and properties of soluble antigen-antibody complex (horseradish peroxidase-antihorseradish peroxidase) and its use in the identification of spirochetes. J Histochem Cytochem 18:315-333.

Uchida K, Tsuzaki N, Nagatsu T, Kohsaka S (1992) Tetrahydrobiopterin-dependent functional recovery in 6-hydroxydopaminetreated rats by intracerebral grafting of fibroblasts transfected with tyrosine hydroxylase cDNA. Dev Neurosci 14:173-180.

Ungerstedt U, Arbuthnott GW (1970) Quantitative recording of rotational behavior in rats after 6-hydroxy-dopamine lesions of the nigrostriatal dopamine system. Brain Res 24:485-493.

Widner H, Tetrud J, Rehncrona S, Snow B, Brundin P, Gustavii B, Björklund A, Lindvall O, Langston JW (1992) Bilateral fetal mesencephalic grafting in two patients with Parkinsonism induced by 1-methyl-4-phenyl-1,2,3,6-tetrahydropyridine (MPTP). N Engl J Med 327:1556-1563.

Wolff JA, Fisher LJ, Xu L, Jinnah HA, Langlais PJ, Iuvone PM, O’Malley KL, Rosenberg MB, Shimohama S, Friedmann T, Gage FH (1989) Grafting fibroblasts genetically modified to produce L-dopa in a rat model of Parkinson's disease. Proc Natl Acad Sci USA 86:9011-9014.

Yang Y, Nunes FA, Berencsi K, Furth EE, Gonczol E, Wilson JM (1994) Cellular immunity to viral antigens limits E1-deleted adenoviruses for gene therapy. Proc Natl Acad Sci USA 91:4407-4411. 